\title{
The Arabidopsis SENESCENCE-ASSOCIATED GENE 13 Regulates Dark-Induced Senescence and Plays Contrasting Roles in Defense Against Bacterial and Fungal Pathogens
}

\author{
Nikhilesh Dhar, ${ }^{1,2}$ Julie Caruana, ${ }^{1,3}$ Irmak Erdem, ${ }^{1}$ Krishna V. Subbarao, ${ }^{2}$ Steven J. Klosterman, ${ }^{4}$ and \\ Ramesh Raina ${ }^{1, \dagger}$ \\ ${ }^{1}$ Department of Biology, Syracuse University, Syracuse, NY 13210, U.S.A. \\ ${ }^{2}$ Department of Plant Pathology, University of California, Davis, Salinas, CA 93905, U.S.A. \\ ${ }^{3}$ ASEE Postdoctoral Fellow, Naval Research Lab, Washington DC 20375, U.S.A. \\ ${ }^{4}$ USDA-ARS, 1636 E. Alisal St, Salinas, CA 93905, U.S.A.
}

Accepted 12 February 2020.

\begin{abstract}
SENESCENCE-ASSOCIATED GENE 13 (SAG13) of Arabidopsis is a widely conserved gene of unknown function that has been extensively used as a marker of plant senescence. SAG13 induction occurs during plant cell death processes, including senescence and hypersensitive response, a type of programmed cell death that occurs in response to pathogens. This implies that $S A G 13$ expression is regulated through at least two different signaling pathways affecting these two different processes. Our work highlights a contrasting role for SAG13 in regulating resistance against disease-causing biotrophic bacterial and necrotrophic fungal pathogens with contrasting infection strategies. We provide further evidence that SAG13 is not only induced during oxidative stress but also plays a role in protecting the plant against other stresses. SAG13 is also required for normal seed germination, seedling growth, and anthocyanin accumulation. The work presented here provides evidence for the role of SAG13 in regulating multiple plant processes including senescence, defense, seed germination, and abiotic stress responses. $S A G 13$ is a valuable molecular marker for these processes and is conserved in multiple plant species, and this knowledge has important implications for crop improvement.
\end{abstract}

Keywords: abiotic stress, anthocyanin pigments, biotic stress, defense response, disease resistance, hypersensitive response, programmed cell death, reactive oxygen species, senescence, senescence-associated gene $(S A G)$

${ }^{\dagger}$ Corresponding author: R. Raina; raraina@syr.edu

Funding: Work in the laboratory of R. Raina was supported by a grant from the National Science Foundation Division of Integrative Organismal Systems (IOS-1146128).

*The $\boldsymbol{e}$-Xtra logo stands for "electronic extra" and indicates that five supplementary figures and one supplementary table are published online.

The author(s) declare no conflict of interest.

๑) 2020 The American Phytopathological Society
Plants synthesize their own food but, due to their sessile nature, depletion and subsequent scarcity of nutrients over time becomes a limiting factor in acquisition of resources to support regular growth and development. Hence, plants recycle nutrients from tissues that are undergoing different forms of programmed cell death (PCD), and both processes occur either as a part of developmental progression during its life cycle or in response to external stimuli (Thomas 2013). Such cell death processes in plants include autophagy, xylogenesis, hypersensitive response (HR), necrosis, apoptosis, and senescence, while there may be subtle or major differences in how each is executed, all are associated with either a developmental program or stress-induced responses (Love et al. 2008; Pennell and Lamb 1997). Senescence is a developmentally regulated PCD process in plants that is visually manifested in aging plant leaves, maturing flowers, and ripening fruits (Kabbage et al. 2017; Wojciechowska et al. 2018). During the highly regulated progression of monocarpic senescence in annual plants, nutrients are transported from the senescing leaves to the developing seeds, signifying a switch from vegetative growth to reproductive growth (Davies and Gan 2012).

Numerous genes are differentially regulated spatiotemporally, in a developmentally and genetically coordinated manner, to protect plants and their resources. Candidate genes for such roles are involved in osmoregulation, dismantling of membrane bound organelles, breakdown of photosynthetic apparatus, metabolism, and transport of nutrients (including carbohydrates, proteins, and lipids), amelioration of reactive oxygen species (ROS) generated as a result of cell death, as well as those involved in defense responses against pests (Coll et al. 2011; Dickman and Fluhr 2013; Himelblau and Amasino 2001; Maillard et al. 2015). Studies in search of genes that are regulated during senescence has led to the identification of senescence-associated genes (SAGs) (Espinoza et al. 2007; Lohman et al. 1994; Park et al. 1998). Unsurprisingly, many candidates that were initially identified as SAGs in genetic screens have now been subsequently implicated in various other cellular responses in addition to their role in senescence (Miller et al. 1999; Quirino et al. 1999; Weaver et al. 1998).

During the progression of senescence, dying cells and organelles are delicately dismantled and this is coupled with an intricate balance between salvaging the nutrients from the disintegrating cells while inhibiting opportunistic pathogen 
infections during this window of time (Breeze et al. 2008, 2011). Thus, it is not surprising that multiple $S A G s$, including SAG15 (ERD1), SAG21 (AtLEA5), SAG25 (ELI3), and SAG101, have been reported to be involved in defense responses against opportunistic pathogens. These genes are differentially regulated during senescence to prevent pathogen interference that might otherwise lead to undesirable consequences for the plant (Chen et al. 2015; Dickman and Fluhr 2013; Greenberg and Ausubel 1993; Salleh et al. 2012).

Before the onset of visible yellowing of the leaves coinciding with the increasing efflux of nutrients (transport) to the developing organs of the plant, adjoining cells in the immediate vicinity must be protected from harmful by-products including free radicals and toxic intermediates generated by the progressively deteriorating cellular apparatus undergoing senescence (Mattila et al. 2018). Any misregulation of this process can lead to deleterious consequences for the plant, including uninhibited cell death, which may be local or may spread quickly, spiraling out of regulated control. The importance of tight regulatory control of this process is highlighted by the dysregulated cell death in the lesion mimic mutants (LMMs) (Greenberg et al. 1994; Lorrain et al. 2003). Moreover, many plant genes that have roles in regulating cell death processes (including senescence) are also differentially regulated in response to biotic as well as abiotic stresses (including osmotic stress, high irradiance and prolonged darkness, cold and heat, flooding and drought, and oxidative stress), leading to one form of cell death or another (Lorrain et al. 2003). Thus, components (including products of many $S A G s$ ) involved in the regulation of cell death are more likely to function in protecting plants under unfavorable growth conditions that cause abiotic stresses. For example, many genes involved in processes that contribute toward ameliorating drought, saline, and oxidative stresses (higher atmospheric ozone and ROS), ionizing radiation (UV rays), biosynthesis of antioxidants, osmoprotection, or DNA damage repair have also been identified as $S A G s$ in various screens (Chen et al. 2017; Seo et al. 2011; Weaver et al. 1998). Even though specific sets of genes are differentially regulated during whole plant and dark-induced senescence (Oh et al. 1996; Park et al. 1998; Weaver and Amasino 2001) and the process of senescence has been studied extensively, resulting in development of many widely used senescence markers, the roles of many of these genes either during senescence or in crosstalk with other cellular processes is only being uncovered in recent years ( $\mathrm{Li}$ et al. 2012; Wang et al. 2019). Functional characterizations of such SAGs are adding to our everincreasing understanding of such interconnected complex genetic networks underlying these diverse plant processes.

Although SAG13 is expressed early during developmental senescence (Weaver et al. 1998), is induced upon dark treatment (Jing et al. 2008), and has been assigned to a subgroup of SAGs specific for ROS-induced cell death and senescence (Brodersen et al. 2002; John et al. 2001; Miller et al. 1999), no function has ever been assigned to this widely used marker gene. Furthermore, The Arabidopsis Information Resource (TAIR) annotation of SAG13 (At2g29350) describes it as a SAG likely to encode a putative short-chain alcohol dehydrogenase that has been variably predicted to have a putative tropinone reductase function, but biochemical studies have found no functional evidence in support of this prediction (Brock et al. 2008). In this study, we provide experimental evidence in support of multiple roles for $S A G 13$. The expression of this gene has been extensively used as a molecular marker preceding the onset of visible senescence in Arabidopsis thaliana (Brodersen et al. 2002; Chen et al. 2017; Espinoza et al. 2007; Jing et al. 2005, 2008; John et al. 2001; Lohman et al. 1994; Miller et al. 1999; Weaver and Amasino
2001; Weaver et al. 1998). But homologs of $S A G 13$ have since been identified in other plant species, including rice, grapes, and corn, and their expression has routinely served as senescence markers (Espinoza et al. 2007). We hypothesized that, since different types of cell death response (including diseaserelated, HR, and necrosis), are promoted during various plant pathogen interactions, SAG13 might not be just induced during these processes but may have an active role in regulating
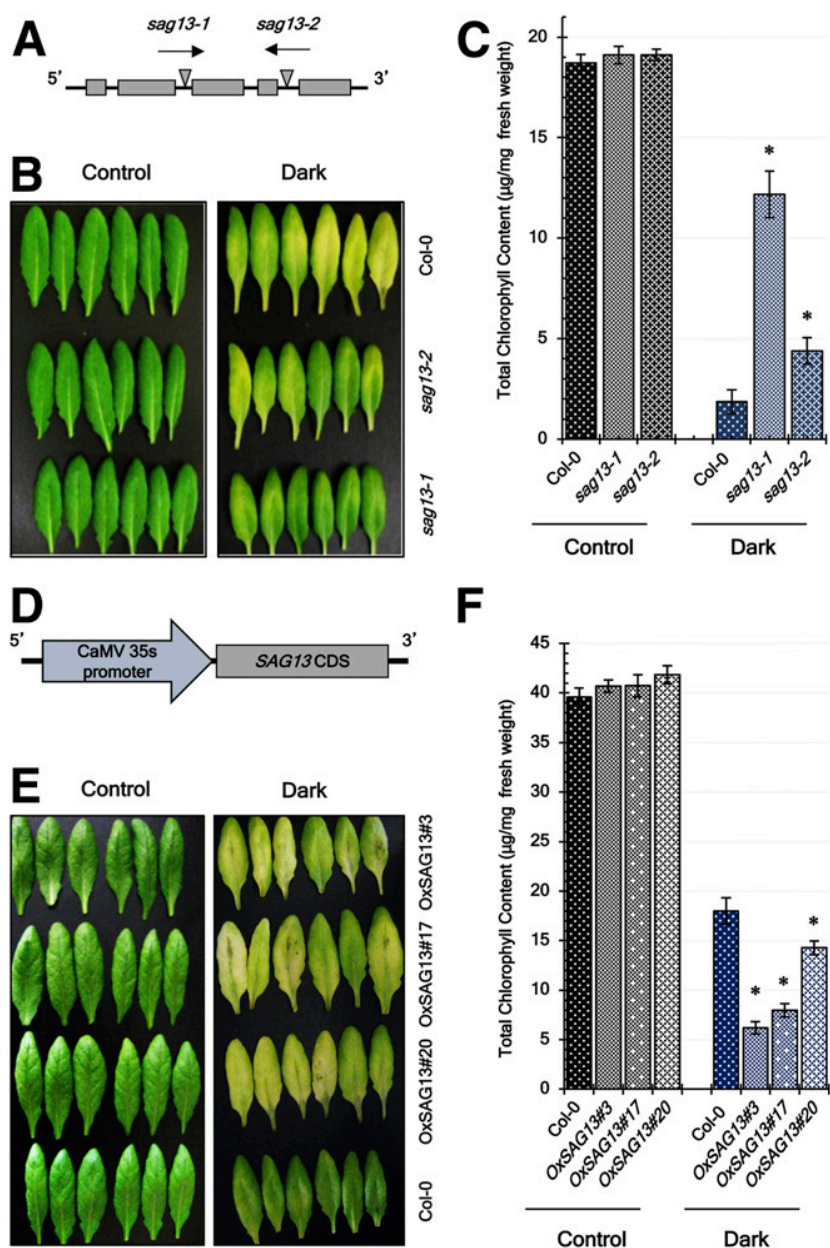

$\mathbf{F}$

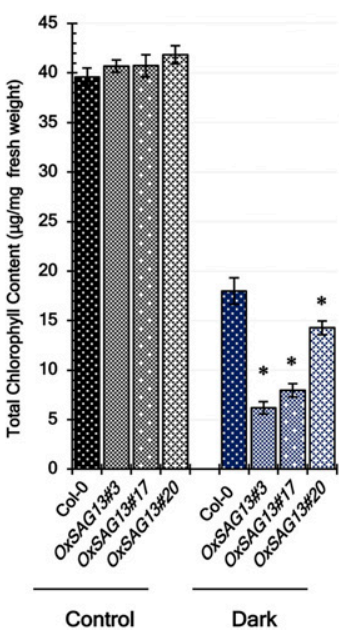

Fig. 1. Response of sag13 mutants in Arabidopsis and constitutive expression of SAG13 plants during dark-induced senescence. A, Schematic diagram depicting location of sag 13-1 and sag13-2 T-DNA insertions in the Arabidopsis SAG13. Triangles represent the location while arrows indicate the direction of the T-DNA insertions. The black line indicates the introns while gray rectangles represent the exons. B, Response of the wild-type Col-0 and sag 13 mutant leaves to dark treatment. Fully expanded rosette leaves of four-to-five-week-old soil-grown plants of the indicated genotypes were taken in triplicates on a sterile Whatman no. 3 filter paper moistened with enough double-distilled $\mathrm{H}_{2} \mathrm{O}$ to retain humidity inside a square Petri dish. Two plates were then tightly sealed with parafilm, were wrapped in a double layer of aluminum foil, and were kept on the same rack as the trays in the plant-growth room. Control treatment was done with a third plate under light, kept side by side to the dark-treated plates under long-day conditions at room temperature. Leaves were monitored for the progression of senescence and the picture was taken immediately upon the appearance of visible difference. $\mathbf{C}$, Chlorophyll content of leaves pictured in B. Average chlorophyll content \pm standard error of the mean is shown for at least nine plants per genotype. Asterisks indicate $P<0.05$ for significant difference of mutants compared with the wild-type Col-0. The experiment was repeated at least three times with similar results. D, Schematic diagram depicting construction of SAG13 constitutive expression lines. CaMV 35S promoter $=$ cauliflower mosaic virus $35 \mathrm{~S}$ promoter, $\mathrm{CDS}=$ coding sequence. E, Response of the wild-type Col- 0 and SAG13 constitutive expression lines to dark treatment and $\mathbf{F}$, the chlorophyll content of the leaves pictured in $\mathrm{E}$. 
responses to such pathogen challenges. Thus, the work presented here explores the role of SAG13 in defense against biotrophic bacterial pathogens Pseudomonas syringae pv. tomato DC3000 (DC3000) and Pseudomonas syringae pv. maculicola ES4326 (ES4326) as well as against the necrotrophic fungal pathogen Botrytis cinerea, all of which are known to cause disease and subsequent cell death in the compatible hosts, including Arabidopsis thaliana. Additionally, we functionally characterized this widely used senescence marker gene and provide evidence that it is not only induced during senescence but is also involved in regulating senescence, seed germination, and seedling development during oxidative stress, and has a potential protective role in regulating response to ROS combined with light stress by regulating the biosynthesis of protective anthocyanin pigments. Furthermore, this current work sheds light on the signaling and networks of genetic components involved in regulation of SAG13 in plants during biotic
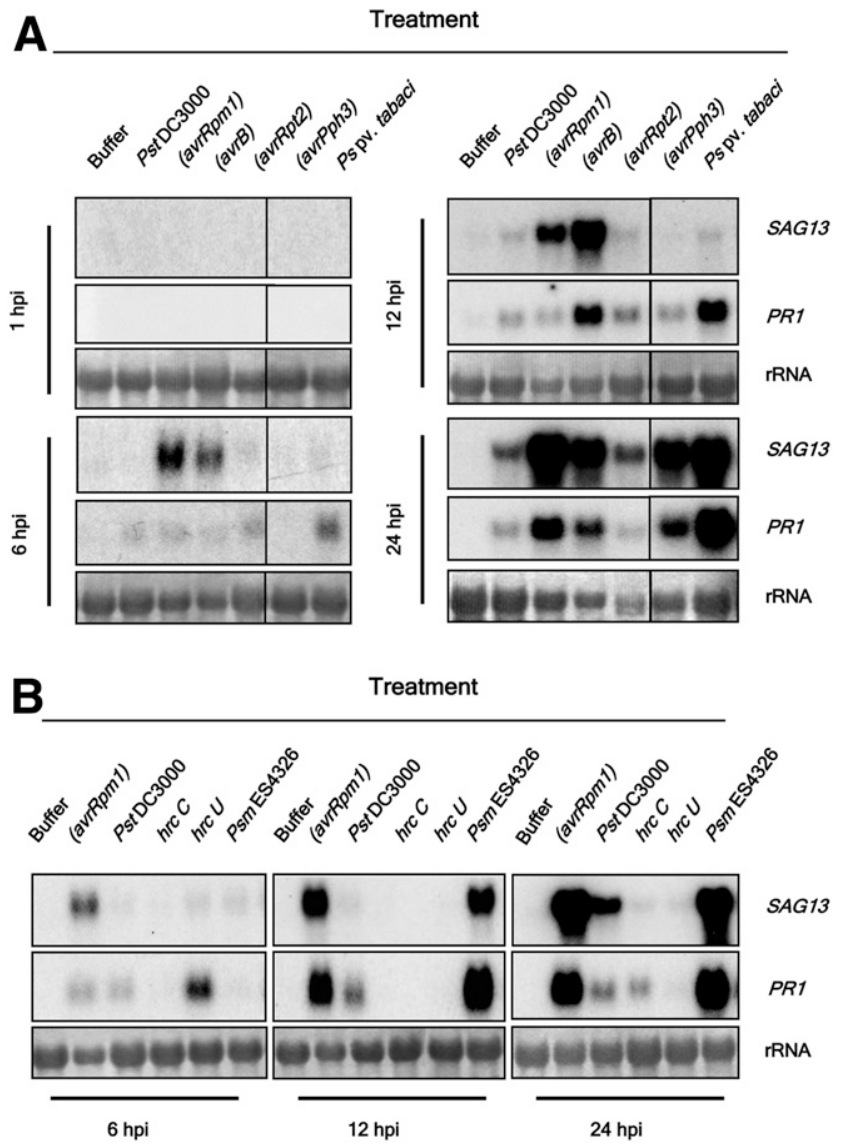

Fig. 2. Bacterial pathogens induce expression of Arabidopsis SAG13 in a type III secretion system (T3SS)-dependent manner. Northern blot analysis of SAG13 expression in the wild-type Col-0 plants in response to different bacterial pathogens. Fully expanded rosette leaves from four-to-five-weekold wild-type Col-0 plants were pressure-infiltrated with a needleless syringe on their abaxial side with a bacterial titer of $5 \times 10^{7} \mathrm{CFU} / \mathrm{ml}$ with the following bacteria: A, Pseudomonas syringae DC3000 and DC3000 carrying the avirulence factors avrRpm1, avrRpt2, avrPph3, the nonhost pathogen $P$. syringae pv. tabaci, and $P$. syringae pv. maculicola ES4326 carrying the avirulence factor $a v r B$ or with B, DC3000 control virulent and avirulent strains plus DC3000 with mutations in $h r c C$ or $h r c U$ and ES4326. Control plants were treated with $10 \mathrm{mM} \mathrm{MgCl}_{2}$ solution alone. Tissue was collected at the indicated hours after treatment (hpi). Total RNA was isolated for Northern blot analysis to measure SAG13 steady state mRNA levels, and membranes were then stripped and hybridized with a $P R 1$ probe. Membranes were stained with methylene blue to indicate relative amounts of RNA in each lane (28S rRNA). Five to six plants were used for each treatment. Results were repeated at least three times with similar results. and abiotic stresses. Since the effect of senescence on crop yield, ripening of fruits, and accumulation of biomass is well established (Gan and Amasino 1995; Wu et al. 2012), our findings provide insight for utilizing this highly conserved and tightly regulated pathogen defense and senescence regulator for the purpose of crop improvement.

\section{RESULTS}

$S A G 13$ is a positive regulator

of dark-induced leaf senescence.

SAG13 was initially identified in Arabidopsis as a gene upregulated during developmental senescence (Lohman et al. 1994; Quirino et al. 1999) and has been used as a marker of early developmental senescence and PCD in Arabidopsis and other plant species (Brodersen et al. 2002; Espinoza et al. 2007). Our Northern blot analysis confirms the senescencespecific induction of $S A G 13$ in senescing rosette leaves but not in other plant parts tested (Supplementary Fig. S1). To further characterize SAG13, we identified two loss-of-function T-DNA mutant lines from the SALK and SAIL seed collections and have labeled them as sag13-1 and sag13-2, respectively (Fig. 1A). Both mutations are within SAG13 and are expected to disrupt its expression; sag13-1 is in the second intron, while sag 13-2 is in the fourth (last) intron. This expectation was verified with Northern blot analysis of the mutant lines (Supplementary Fig. S2A). To study the effect of ectopic expression of $S A G 13$, we constructed ectopic overexpression lines (Fig. 1D) and selected three independent lines (Supplementary Fig. S2B) for further analysis.

To examine the role of $S A G 13$ in regulating senescence, we examined both wild-type Col-0 and sag 13 mutant plants in a dark-induced senescence assay (Oh et al. 1997). The leaves of sag13 mutants remained green for a longer period than the wild-type Col-0 plants (Fig. 1B) and retained higher levels of chlorophyll (Fig. 1C), indicating a reduction of dark-induced senescence in sag13 mutants. In contrast, when leaves from plants from three independent transgenic lines ectopically expressing SAG13 expressing SAG13 complementary DNA (cDNA) from a constitutive cauliflower mosaic virus (CaMV) $35 \mathrm{~S}$ promoter, denoted as OxSAG13 (Fig. 1D), were taken in an independent experiment, such leaves displayed accelerated senescence (Fig. 1E) and retained less total chlorophyll than the control Col-0 plants (Fig. 1F). It should be noted that, under similar experimental conditions, the senescence phenotype for sag 13 mutants in a dark-induced detached-leaf senescence assay usually developed a day to two later than the Col-0 control, while the senescence phenotype of the ectopically expressing OxSAG13 plants consistently developed two to three days earlier with respect to the wild-type Col-0 control plants. Taken together, these results suggest that SAG13 is a positive regulator of dark-induced senescence in Arabidopsis.

\section{SAG13 is a pathogen-inducible gene requiring}

a functional bacterial type III secretion system (T3SS).

We found that $S A G 13$ is induced rapidly and strongly in response to avirulent pathogens DC3000 (avrRpml), ES4326 (avrB), DC3000 (avrRpt2), and DC3000 (avrPph3), which stimulated HR in incompatible interactions, compared with its slower induction with virulent pathogens DC3000 and ES4326 that caused disease in compatible interactions (Fig. 2A and B). These induction kinetics are similar to the expression of many defense genes including PATHOGENESIS RELATED 1 (PRI). Although $S A G 13$ was not induced in buffer-treated control plants, it was strongly induced in response to the nonhost pathogen Pseudomonas syringae pv. tabaci (Fig. 2A), though at a later 
timepoint than with the avirulent pathogens. This is most likely due to cell death resulting from HR as a defense response in the nonhost Arabidopsis (Senthil-Kumar and Mysore 2013). Interestingly, SAG13 was induced robustly in response to bacteriaderived flg22 peptide (Supplementary Fig. S3A), presumably due to the activation of basal defense and production of ROS as a defense response through the pathogen-associated molecular pattern (PAMP)-triggered immunity, which can be attributed to the use of a higher concentration of the flg22 elicitor (Robatzek et al. 2006).

Among various other strategies, bacterial pathogens like DC3000 and ES4326 use an array of virulence factors delivered via a T3SS to bypass plant defense mechanisms and cause disease. This molecular appendage penetrates the plant cell membrane delivering the pathogen effectors directly inside the host cell. These effector molecules, in turn, alter the host physiology, leading to disease and subsequent cell death that results in the release of nutrients to the apoplastic space, which is then utilized by these foliar pathogens as a source of energy to drive their growth and infection (Alfano and Collmer 1997). Therefore, we tested whether the induction of $S A G 13$ in response to these pathogens was caused by the perception of cell-surface PAMPs or whether there is a specific requirement for virulence factors delivered through the T3SS. Wild-type Col-0 plants were infiltrated with strains of DC3000 lacking a functional T3SS, DC3000 $(h r c C)$ and DC3000 $(h r c U)$. These pathogens were strongly compromised in their ability to induce SAG13 (Fig. 2B) during the pathogen-induced expression of SAG13.

A primary challenge with a pathogen (avirulent or virulent) causes activation of defense responses systemically in tissues further away from the site of infection (Durrant and Dong 2004). This preconditioning results in a faster defense response in the face of a subsequent pathogen challenge and is known as systemic acquired resistance (SAR) (Cao et al. 1997). Since we showed that $S A G 13$ induction at the site of local infection closely follows that of $P R 1$, we wanted to test whether such activation in systemic defense responses also results in the activation of $S A G 13$ in the distal tissues. Hence, we assessed SAG13 transcription levels in tissues after an initial challenge of primary tissue with the avirulent pathogen DC3000 ( avrRpml). Interestingly, $S A G 13$ was not induced in distal tissues (Supplementary Fig. S3B), indicating that $S A G 13$, unlike $P R 1$, is not altered in distal tissues in response to pathogen-induced SAR. Pathogen-mediated induction of SAG13 during incompatible interaction resulting in HR coincides with a massive oxidative burst and immediate cell death in the local tissues, accompanied by the activation of defense-related genes. The resulting SAR from such an event usually leads to activation of defense response sans cell death in the distal tissues. Since SAG13 induction was absent in SAR tissues in the non-pathogen challenged distal tissues during a heightened state of defense response, it is likely that $S A G 13$ upregulation in the local infected tissue rather serves in a capacity to protect the host cell or tissues subjected to stress that lead to cell death. These results demonstrate that $S A G 13$ is specifically induced upon the activation of local defense responses and may play an active role in plant defense response.

\section{$S A G 13$ is a negative regulator of defense against biotrophic bacterial pathogens.}

Since $S A G 13$ was strongly induced at a later stage ( $24 \mathrm{~h}$ posttreatment [hpt]) in response to virulent bacterial pathogens (Fig. 2A and B), we wanted to determine whether this upregulation is a result of activation of defense and cell death responses in general or if $S A G 13$ has an active role in defense against these specific virulent bacterial pathogens. Hence, we challenged sag 13 mutants with the virulent bacterial pathogens DC3000 and ES4326 and monitored their growth. The sag13 knockout mutants were more resistant to both pathogens in comparison with wild-type Col-0 plants (Fig. 3A and B). We further explored the effect of $S A G 13$ overexpression in mediating defense responses against these pathogens. We challenged three independent SAG13 overexpression lines with DC3000 and observed that all were five- to seven-fold more susceptible, which is consistent with the resistance phenotype observed in sag13 loss-of-function mutants (Fig. 3C and D). These results suggest that $S A G 13$ is a negative regulator of defense against these biotrophic bacterial pathogens.

\section{$S A G 13$ is a positive regulator of defense} against necrotrophic fungal pathogen Botrytis cinerea.

Infection by Botrytis cinerea results in necrotic cell death and causes gray mold in Arabidopsis (Ferrari et al. 2003;
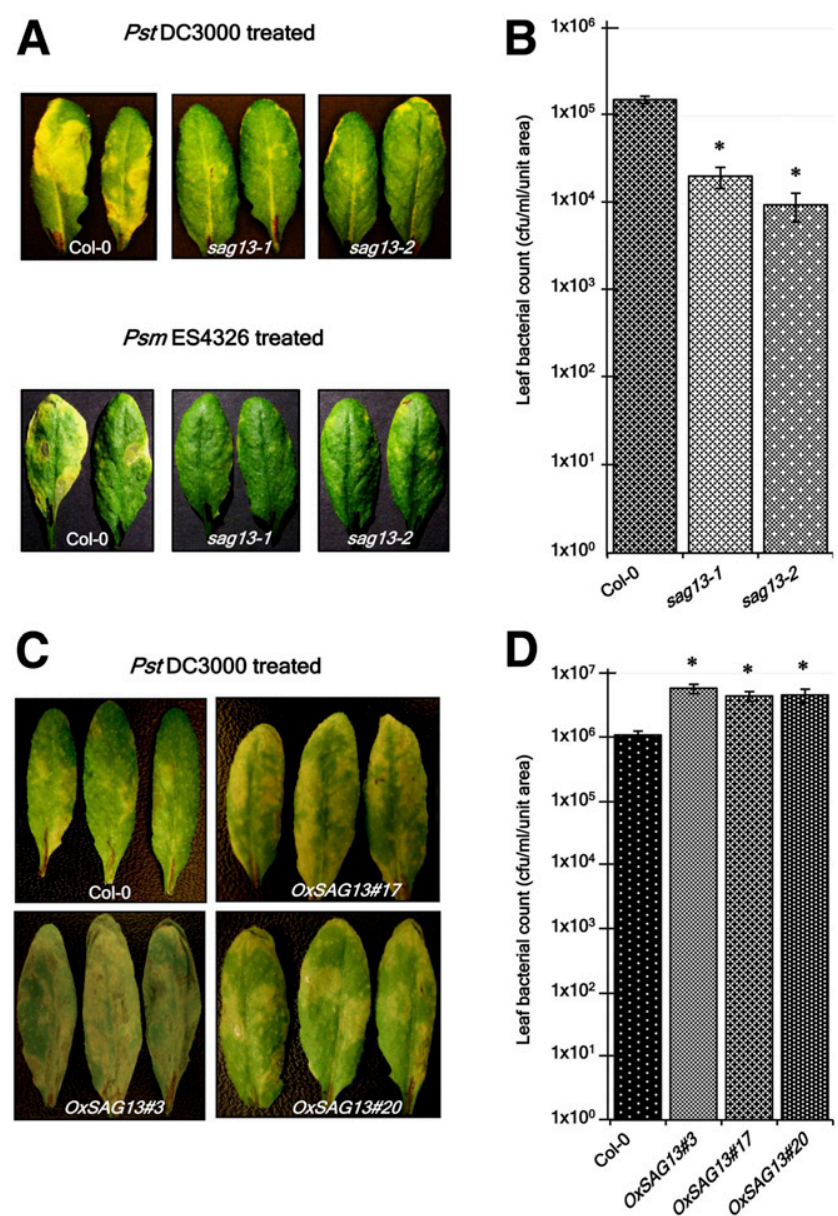

Fig. 3. SAG13 loss-of-function and ectopic overexpression lines show altered defense responses to bacterial pathogens Pseudomonas syringae pv. tomato DC3000 (DC3000) and P. syringae pv. maculicola ES4326 (ES4326). A and C, Pathogen growth assays were performed for sag13 mutants with DC3000 and ES4326 and for SAG13 overexpression lines with DC3000, respectively. Four-to-five-week-old plants from each genotype were pressure-infiltrated with a needleless syringe on the abaxial side at a titer of $5 \times 10^{5} \mathrm{CFU} / \mathrm{ml}$ with the indicated pathogens. The trays were covered with a transparent dome for 3 to $6 \mathrm{~h}$ to retain high humidity. Pictures were taken upon the appearance of visible disease symptoms in terms of leaf yellowing and water-soaked lesions. B and D, Bacterial count for plants inoculated with DC3000 in A and C. Average bacterial growth \pm standard error of the mean for at least nine plants per genotype is graphed. Asterisk indicates $P<0.05$ for significant difference of mutants compared with the wild-type Col-0. The experiment was repeated at least three times with similar results. 
Glazebrook 2005). Previous studies have revealed that $S A G 13$ is induced by jasmonic acid (JA) and ethylene (ET), hormones that are involved in defense against necrotrophic pathogens (Chen et al. 2017; Jing et al. 2005; Weaver et al. 1998). The APETALA2/ET RESPONSE FACTOR (AP2/ERF) domain transcription factor integrates JA and ET signal transduction pathways for a synergistic activation of a specific set of defense genes (Pré et al. 2008). This study also highlighted that a lossof-function mutation in OCTADECANOID-RESPONSIVE ARABIDOPSIS AP2/ERF 59 (ORA59) led to susceptibility to the necrotrophic fungus $B$. cinerea, while constitutive expression led to resistance. Analysis of the microarray data for genes
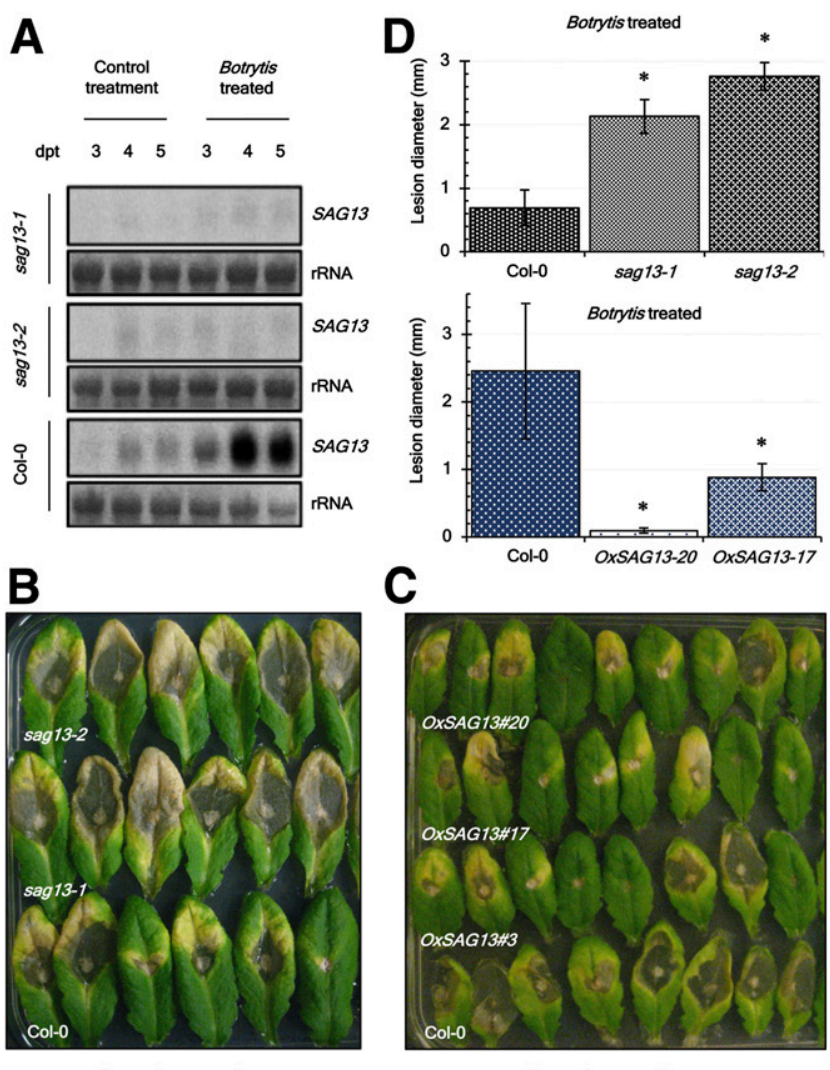

Botrytis treated

Botrytis treated

Fig. 4. The Arabidopsis SAG13 is induced by Botrytis cinerea and is required for resistance against it. A, Northern blot analysis of SAG13 expression in sag 13 mutants and the wild-type Col-0 plants in response to the fungal pathogen Botrytis cinerea. Two fully expanded rosette leaves from four-to-five-week old sag13-1, sag13-2, and the wild-type Col-0 plants were drop-inoculated with $B$. cinerea at a titer of $5 \times 10^{5}$ spores $/ \mathrm{ml}$ suspended in potato dextrose broth (PDB). Control plants were inoculated with only PDB. Plates from two replicates were sealed tightly with parafilm to retain humidity and were incubated at room temperature under light until collection at the indicated days post-treatment (dpt). mRNA was isolated for Northern blot analysis to measure SAG13 steady state mRNA levels. Membranes were stained with methylene blue to indicate relative amounts of RNA in each lane (28S $r R N A$ ). Eight to ten plants were used for each treatment. The experiment was repeated twice with similar results. B and $\mathbf{C}$, Growth of B. cinerea in sag 13 mutants or SAG13 ectopic overexpression plants, respectively. Seven to nine rosette leaves from four-to-five-week-old plants were drop-inoculated with $B$. cinerea at a titer of $5 \times 10^{5}$ spores $/ \mathrm{ml}$ suspended in water. Plates from two replicates were sealed tightly with parafilm to retain humidity and were incubated at room temperature under light. Leaves were photographed at $3 \mathrm{dpt}(\mathrm{B})$ or $5 \mathrm{dpt}(\mathrm{C})$. Eight to ten plants were used for each treatment. The experiment was repeated at least three times with similar results. D, Average lesion diameter \pm standard error of the mean is graphed for the indicated genotypes treated with $B$. cinerea as shown in B and C. Asterisks indicate $P<0.05$ for significant differences as compared with the wild-type Col-0. Eight to ten plants were used for each treatment. The experiment was repeated at least twice with similar results. upregulated in XVE-ORA59 (estradiol-responsive ORA59 overexpression) lines in the study by Pré et al. (2008) revealed SAG13 as one of the many genes that was induced in the untreated ORA59 overexpression lines. Furthermore, the same study revealed that the AP2/ERF domain transcription factor controls resistance against the necrotrophic fungus $B$. cinerea. These observations prompted us to test whether SAG13 expression is affected during infection with $B$. cinerea and if $S A G 13$ plays a role in resistance against this fungus. After challenging the wild-type Col-0 plants with $B$. cinerea, SAG13 is strongly induced (Fig. 4A). Additionally, we discovered that loss-of-function sag13 mutants were more susceptible to the fungus than the control Col-0, as seen from the progression of disease with larger lesion sizes and enhanced discoloration (Fig. 4B). Conversely, plants overexpressing SAG13 were more resistant to $B$. cinerea infection since the lesion sizes were consistently smaller than in the wild-type Col-0 plants (Fig. 4C).

\section{$S A G 13$ is upregulated during various processes that are accompanied by enhanced ROS production.}

Loss of chlorophyll and lipid damage during senescence is accompanied by increased expression of $S A G 13, S A G 14$, and $S A G 17$, which is also mirrored during the plant response to UVB radiation (John et al. 2001). The defense response to elevated ROS upon UVB exposure was shown to involve JA and ET signaling pathway components (A.-H.-Mackerness et al. 1999). Furthermore, superoxide radicals but not the derivative $\mathrm{H}_{2} \mathrm{O}_{2}$ were specifically shown as the type of ROS generated during UV treatment leading to the activation of defense-gene expression (A.-H.-Mackerness et al. 2001). Hence, to further explore the possibility of ROS being required for the upregulation of SAG13, we infiltrated wild-type Col-0 plants with various ROS-generating chemicals, including paraquat (PQ), which targets the PS-I in chloroplasts to generate intercellular superoxide that ultimately leads to cell death (Noctor et al. 2016), and 3-AT (3-amino-1, 2, 4-triazole), which promotes accumulation of intracellular superoxide by inhibiting catalases and $\mathrm{H}_{2} \mathrm{O}_{2}$, which can be broken down by catalase. Our results show that $S A G 13$ is strongly induced in response to PQ and moderately induced by 3-AT (Fig. 5A). To further confirm that the PQ-mediated superoxide radical induces $S A G 13$, we used transcriptional reporter transgenic lines that express the $\beta$-glucuronidase (GUS) reporter gene under the control of the $S A G 13$ promoter. These $S A G 13$ promoter::GUS reporter lines confirmed $S A G 13$ expression after treatment with the above chemicals.

These results show that $S A G 13$ is induced by superoxide radicals. To test whether $S A G 13$ is required for resistance to ROS-induced stress, we performed a PQ sensitivity assay with sag13 seeds, with the wild-type Col-0 as control. We found that sag13 seeds have increased sensitivity to $\mathrm{PQ}$, as indicated by reduced germination efficiency, reduction of root growth, and discoloration of the cotyledons and leaves as compared with the control Col-0 (Fig. 5C). These results imply that one of the biological functions of SAG13 in plants may involve ameliorating the effects of ROS and protecting the plant in situations in which enhanced ROS signaling is at play, including cell death, senescence, pathogen infection, and photo-oxidative stress.

SAG13 upregulation has been observed during senescence, a process that is accompanied by a heightened defense response to protect plants from opportunistic pathogens as well as from deregulation of cellular machinery during pathogen-induced HR type or disease-caused death (Hofius et al. 2007; Williams and Dickman 2008). We tested SAG13 expression in various LMMs and found that $S A G 13$ is upregulated in leaves with 
lesions more strongly compared with the leaves without lesions that have reduced levels of ROS and cell death (Fig. 5B).

Flavonoids, including anthocyanin, are known to accumulate and provide protection in response to pathogens, ROS, photooxidation, and in the senescing leaves of plants (Glässgen et al. 1998; Landi et al. 2015; Lu et al. 2017; Zhang et al. 2013). During the senescence experiments, we had observed that untreated leaves left in continuous high light showed increased accumulation of anthocyanin in the wild-type Col- 0 control, but this same accumulation was not observed for the sag $13 \mathrm{mu}-$ tants. Further, we observed signs of photobleaching on the leaves of the sag13 mutants in the light-treated plates but not in the control Col-0. During the progression of detached leaf senescence assays, we noticed that detached leaves left under light eventually showed differential accumulation of anthocyanin pigments. This phenotype was further accentuated when leaves were left in continuous higher intensity light (150 to $200 \mu \mathrm{mol} \mathrm{m} \mathrm{s}^{-1}$ ) at room temperature for a similar amount of time (Fig. 5D, top). The sag13 mutant leaves accumulated less anthocyanin as compared with the wild-type Col-0 leaves during stress treatments, indicating that $S A G 13$ may be required for anthocyanin production (Fig. 5D). While fungal elicitors have been linked to suppression of anthocyanins (Glässgen et al. 1998), Botrytis susceptibility is reduced due to antioxidant production (especially anthocyanin accumulation) that alters the spreading of the ROS burst during infection, as seen in tomato (Zhang et al. 2013). Furthermore, biosynthesis and accumulation of anthocyanin has also been proposed as a defense strategy against the fungal pathogen Gymnosporangium yamadai Miyabe, which causes the cedar-apple rust in the Malus crabapple leaves (Lu et al. 2017).
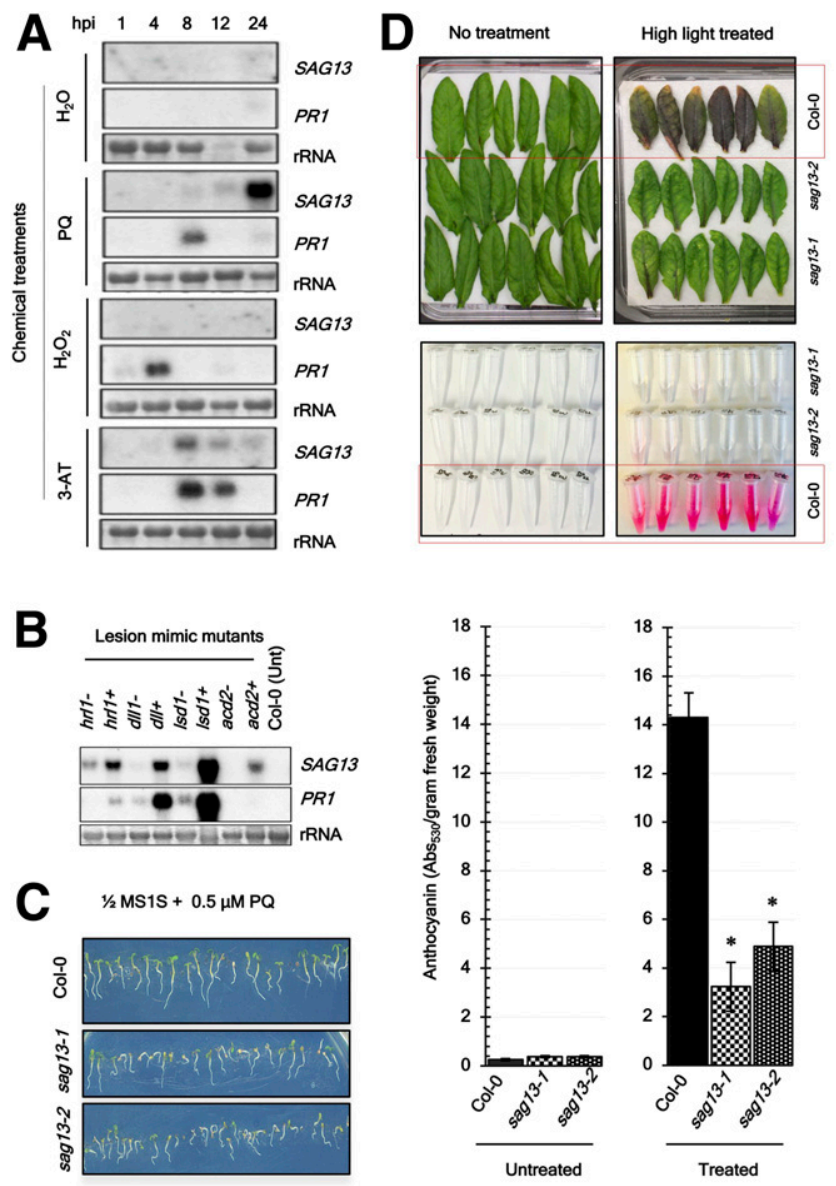

Although there is no visible difference in anthocyanin pigment levels in soil-grown plants of either the untreated control Col-0 or sag13 mutant lines, spectroscopic analysis for the pigment showed that sag 13 leaves routinely averaged slightly more anthocyanin than the wild-type Col-0; however, this difference was found to be statistically insignificant (Fig. 5D). It is possible that an elevated level of ROS in sag 13 mutant plants provides protection against biotrophic bacterial pathogens. This scenario in combination with reduced anthocyanin accumulation during stress predisposes the sag 13 mutants to susceptibility to necrotrophic fungal infection.

\section{Pathogen-mediated induction of $S A G 13$ expression requires components of the $S A$ and ET/JA pathways.}

Since our results revealed that expression of SAG13 is induced by both avirulent and virulent strains of Pseudomonas syringae and contributes to resistance against Pseudomonas spp. as well as Botrytis spp., we were interested in defining the components of the defense-response pathway that might entail such pathogen-mediated responses involving SAG13. We used mutants in the major hormonal signaling pathways that mediate

Fig. 5. SAG13 expression in Arabidopsis is induced in response to reactive oxygen species (ROS), and SAG13 function is required for normal seedling development and accumulation of anthocyanin during oxidative stress. A, Northern blot analysis of SAG13 expression in the wild-type Col-0 plants in response to ROS-inducing chemicals. Fully expanded rosette leaves from four-to-five-week old wild-type Col-0 plants were pressure-infiltrated on the abaxial side, with a needleless syringe, with either paraquat (PQ) $(50 \mu \mathrm{M}), 3$-amino-1, 2, 4-triazole (3-AT) $(10 \mathrm{mM})$, or $\mathrm{H}_{2} \mathrm{O}_{2}(20 \mathrm{mM}) . \mathrm{H}_{2} \mathrm{O}$ was used as control. Tissue was collected at the indicated hours post-treatment (hpi). mRNA was isolated for Northern blot analysis to measure $S A G 13$ steady state mRNA levels, and then, the membrane was stripped and hybridized with a $P R I$ probe. Membranes were stained with methylene blue to indicate relative amounts of RNA in each lane (28S rRNA). Five to six plants were used for each treatment. Results were repeated at least twice with similar results. B, Northern blot analysis of SAG13 expression in lesion mimic mutants (LMMs). Fully expanded rosette leaves with $(+)$ or without $(-)$ visible lesions were collected from four-to-five-week old LMMs. Wild-type Col-0 plants were used as control. mRNA was isolated for Northern blot analysis to measure $S A G 13$ steady state mRNA levels and was then stripped and hybridized with a $P R 1$ probe. Membranes were stained with methylene blue to indicate relative amounts of RNA in each lane $(28 \mathrm{~S}$ $r R N A)$. Five to six plants were used for each genotype. Results were repeated at least twice with similar results. C, Seedling growth of sag 13 mutants and the control Col-0 on one-half Murashige Skoog (1/2-MS) medium ( $\mathrm{pH} 5.8,0.8 \%$ agar) containing PQ. Seeds from each genotype were sterilized, were stratified for 3 to 5 days at $4{ }^{\circ} \mathrm{C}$ to break dormancy, were plated on 1/2-MS (pH 5.8, $0.8 \%$ agar) medium containing $1 \%$ sucrose with $0.5 \mu \mathrm{M}$ of $\mathrm{PQ}$, and were kept under light at room temperature. At least 25 to 35 seeds per genotype were plated. Plates were monitored daily and the picture was taken 4 to 6 days postgermination. The experiment was repeated at least twice with similar results. D, Anthocyanin content in sag 13 mutants and the wild-type Col-0 control. Eight to ten rosette leaves from five-to-six-week-old plants of each genotype were detached and were placed on a sterile Whatman no. 3 filter paper in a square Petri dish. Control leaves were harvested from the same set of plants, just before the extraction of anthocyanin pigments. The filter paper was moistened with enough double-distilled (dd) $\mathrm{H}_{2} \mathrm{O}$ to retain humidity inside the plate. To induce anthocyanin accumulation, plates were sealed and were kept at room temperature under higher intensity cool white light at photosynthetic photon flux density of 150 to $200 \mu \mathrm{mol} \mathrm{m} \mathrm{m}^{-2} \mathrm{~s}^{-1}$ for 14 to 18 days without the addition of any nutrients, except $\mathrm{ddH}_{2} \mathrm{O}$, when necessary. Leaves were monitored for the accumulation of anthocyanin and the image was taken two weeks after treatment. Anthocyanin was extracted from all leaf samples and the average anthocyanin content \pm standard error of the mean was calculated. Asterisks indicate $P<0.05$ for significant difference of mutants compared with Col- 0 control. The experiment was repeated at least three times with similar results. 
defense responses against these pathogens. SA signaling has also been shown to be a major player in defense response against virulent bacterial pathogens like Pseudomonas syringae (Delaney et al. 1994). In our experiments, SA biosynthesis (EDS16 and NahG), accumulation (EDS1, PAD4, and NDR1), and perception (NPR1) (Cao et al. 1994; Dewdney et al. 2000; Feys et al. 2001; Gaffney et al. 1993) were found to be required for virulent pathogen (DC3000)-mediated induction of SAG13. Specifically, SAG13 expression was reduced in mutants that are compromised in SA perception and biosynthesis (i.e., nprl, $n d r l$, eds16, and $g d g 1$ ), while it was completely abolished in mutants that are unable to accumulate SA (i.e., eds1, pad4, and $N a h G$ ) (Fig. 6A). Furthermore, Pseudomonas syringae is known to use a JA mimic, coronatine, to suppress the activation of SA signaling (Zheng et al. 2012). The HR triggered as a result of this resistance and avirulence gene $(R-a v r)$ interaction is also known to involve ET/JA pathway components, which were thus tested for their role in pathogen-triggered SAG13 expression alongside the SA signaling mutants. It should be

\section{A}

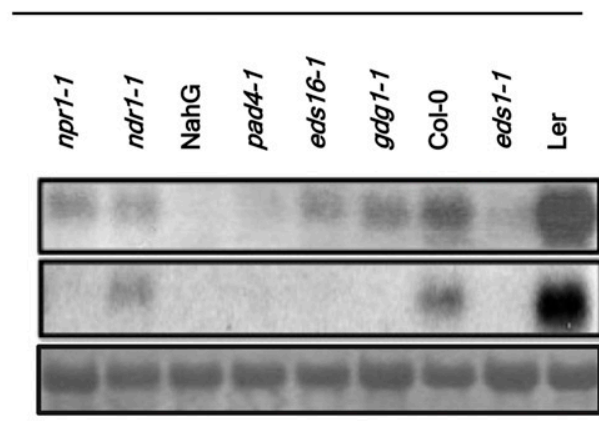

SAG13

PR1

rRNA

\section{B PstDC3000 (avrRpm 1) treated}
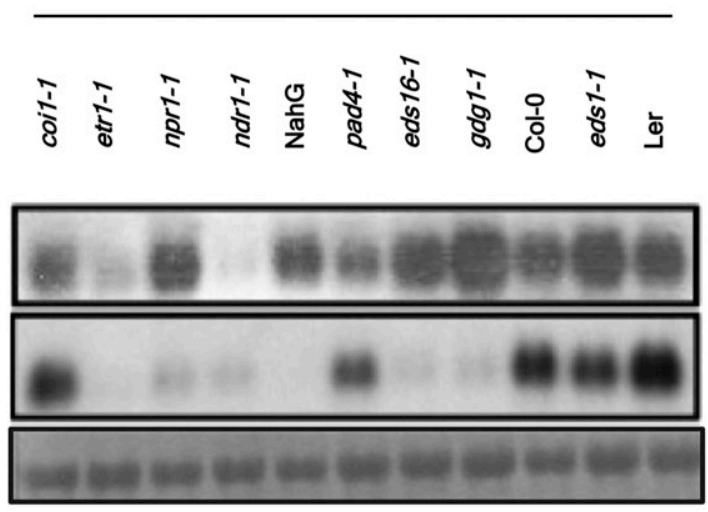

SAG13

C Botrytis cinerea treated
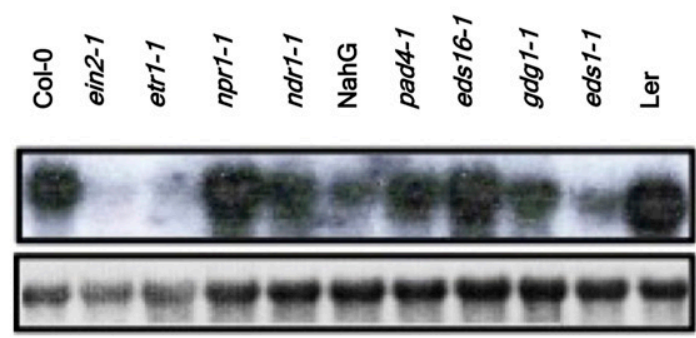

SAG13

rRNA noted that ETRI and COII are receptors for JA and ET, respectively (Cancel and Larsen 2002; Katsir et al. 2008). Furthermore, genetic components of SA-mediated signaling including NDRl are known to be a part of the $R$ activation (Century et al. 1995, 1997) pathway, while $P A D 4$ is central to SA accumulation during $R$ - $a v r$ interaction (Jirage et al. 1999). Our results show that $N D R I$ and ETRI are absolutely required for $S A G 13$ induction, while $C O I 1$ and $P A D 4$ are partially required for $S A G 13$ induction in response to the avirulent pathogen DC3000 (avrRpml) (Fig. 6B). It is also well-documented that ET signaling plays a central role in defense response against necrotrophic fungal pathogens including $B$. cinerea. Strikingly, SAG13 expression in response to Botrytis infection was abolished in the ET signaling mutants etrl and ein2, indicating that $S A G 13$-mediated resistance against this necrotrophic fungal pathogen most likely functions downstream of these master regulators of ET signaling (Fig. 6C).

\section{The $S A G 13$ promoter is upregulated} during development and various stresses.

To analyze the temporal and spatial expression of $S A G 13$, transgenic plants expressing the 1.9-kb sequence upstream of the SAG13 start codon fused to the GUS reporter gene (SAG13 promoter::GUS) were generated in the parental wild-type Col-0 background (Fig. 7A). GUS analysis was carried out at various stages of plant growth, in different organs, and in response to biotic and abiotic stresses. The SAG13 promoter is induced by a bacterial pathogen causing a HR type of cell death (Fig. 7B and C), a fungal pathogen causing necrotrophic cell death (Fig. 7D), mechanical injury (Fig. 7E), and, during cell death, induced specifically by the superoxide-generating chemical PQ (Fig. 7F). These observations are in agreement with the steady state levels of SAG13 expression observed in our Northern blot analyses.

When we examined various tissues and stages of growth, our promoter-reporter analysis showed that SAG13 is not only expressed in senescing leaves as expected but, also, in germinating seedlings and young leaves and in various floral parts, including anther, stigma, petals, ripening siliques, and seeds (Fig. 7G through O). SAG13 promoter upregulation in the anthers (Fig. 7L) is likely due to anther dehiscence, a

Fig. 6. Pathogen-inducible $S A G 13$ expression requires components of salicylic acid (SA) and ethylene (ET) defense signaling pathways in Arabidopsis. A, Northern blot analysis of SAG13 and PR1 expression in mutants of SA, jasmonic acid (JA), and ET signaling pathway components in response to a virulent pathogenic strain of Pseudomonas syringae pv. tomato DC3000 or B, an avirulent strain of DC3000 (avrRpm1). Fully expanded rosette leaves from four-to-five-week-old plants of each genotype were pressure-infiltrated with a needleless syringe, on their abaxial side, with DC3000 at a titer of $5 \times 10^{7} \mathrm{CFU} / \mathrm{ml}$. Control plants were treated with $10 \mathrm{mM} \mathrm{MgCl}{ }_{2}$ solution (data not shown). PRl was used as control for activation of defense responses. Tissue was collected at the $12 \mathrm{~h}$ posttreatment. mRNA was isolated for Northern blot analysis to measure SAG13 steady state mRNA levels, and then, membranes were stripped and hybridized with a $P R 1$ probe. Membranes were stained with methylene blue to indicate relative amounts of RNA in each lane ( $28 S r R N A)$. Five to six plants were used for each treatment. Results were repeated twice with similar results. eds 1 is in Ler (wild type) background. C, Northern blot analysis of SAG13 in defense-related mutants in response to Botrytis cinerea. Four rosette leaves from four-to-five-week-old plants of each genotype were drop-inoculated with $B$. cinerea at a titer of $5 \times 10^{5}$ spores $/ \mathrm{ml}$ suspended in water. Plates from two replicates were sealed tightly with parafilm to retain humidity and leaves were incubated at room temperature under light until collection at 5 days post-treatment. mRNA was isolated for Northern blot analysis to measure SAG13 steady state mRNA levels. The membrane was stained with methylene blue to indicate relative amounts of RNA in each lane ( $28 S$ rRNA). Eight to ten plants were used for each treatment. The experiment was repeated at least three times with similar results. eds 1 is in Ler (wild type) background. 
developmental process determined by ROS signatures (Van Durme and Nowack 2016). Clear induction of SAG13 promoter: GUS was also seen in the senescing petals (Fig. 7L and $\mathrm{M}$ ), another floral organ in which cell death is again preceded by higher levels of ROS and altered levels of oxidative and protective enzymes (Rubinstein 2000). SAG13 promoter expression was detected in the dehiscence zone of the silique as well as the dehiscing silique valves (Fig. $7 \mathrm{~N}$ and $\mathrm{O}$ ). Thus, expression of the
$S A G 13$ promoter in the floral organs is associated with flower senescence, as are various forms of developmental PCD that result from anthesis or pollination of flowers (Rogers 2005).

\section{DISCUSSION}

SAG13 was initially discovered in a screen for genes differentially regulated during senescence (Lohman et al. 1994).

\section{A}

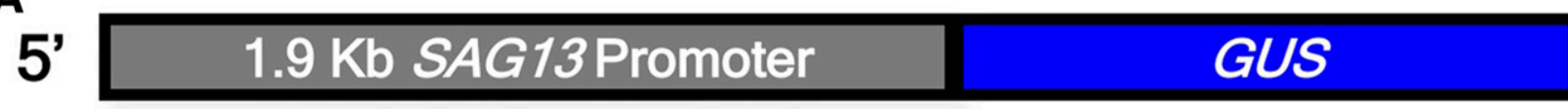

B

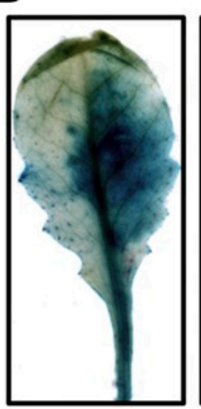

C

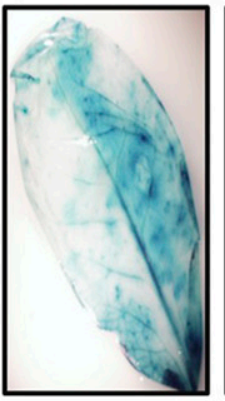

D

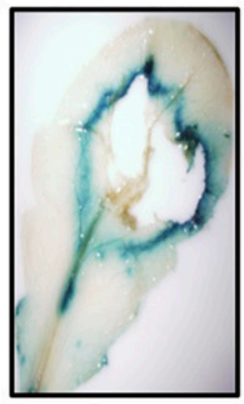

E

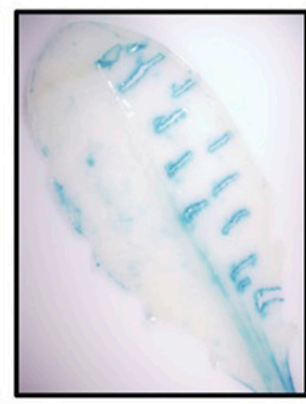

$\mathbf{F}$

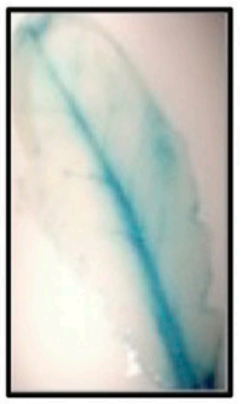

G

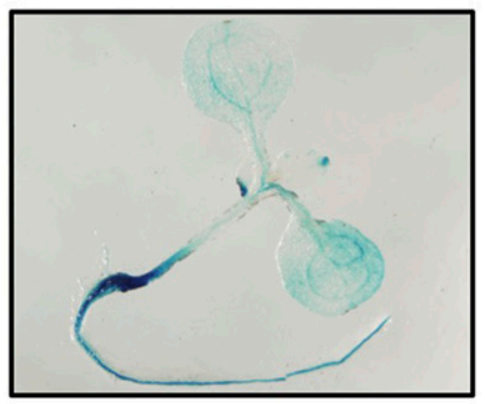

H
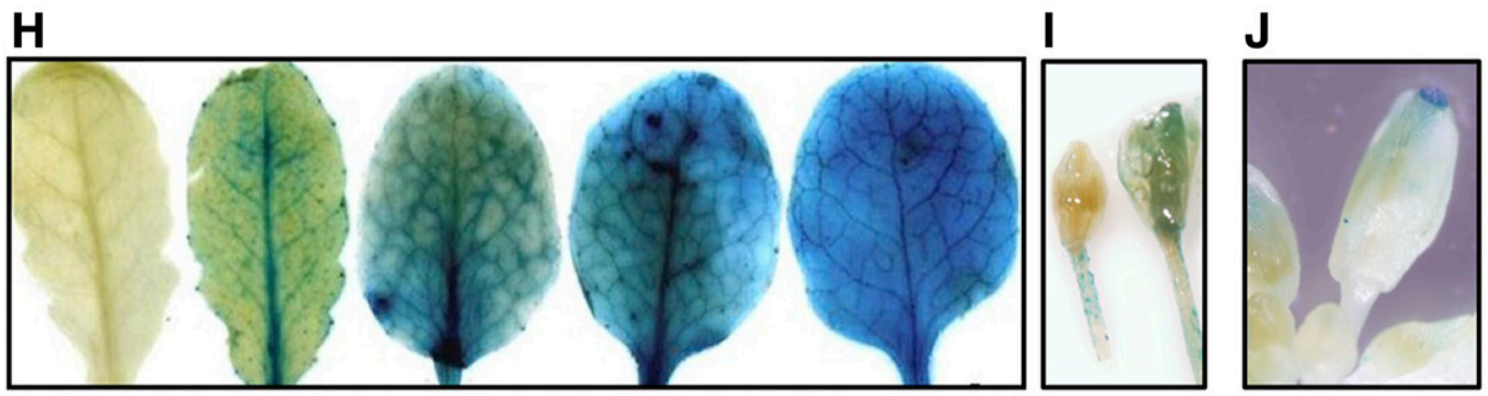

K

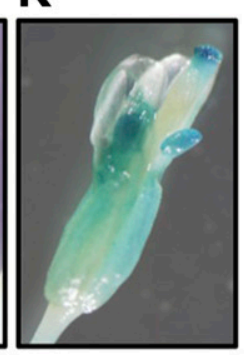

$\mathbf{L}$

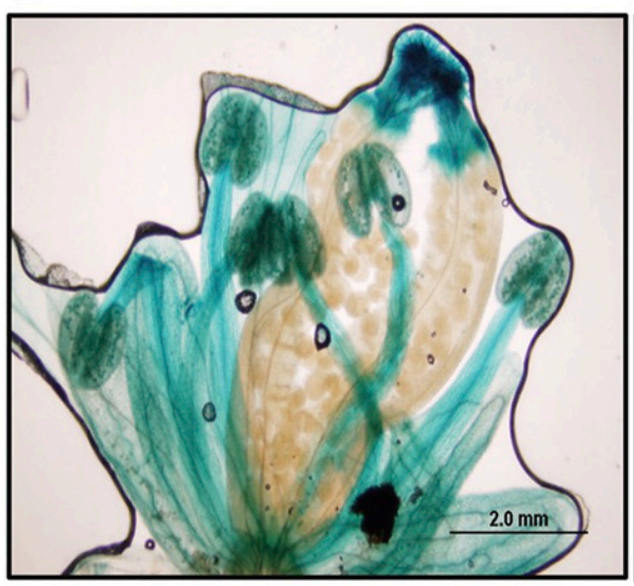

M

$\mathbf{N}$
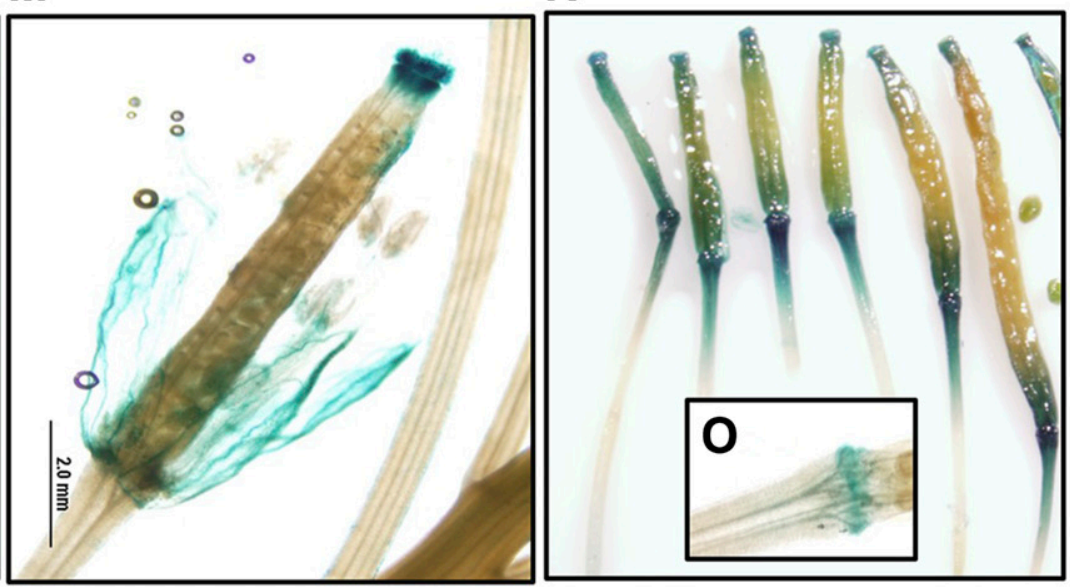

Fig. 7. Temporal and spatial activity of the SAG13 promoter from Arabidopsis. A, Schematic representation of the SAG13 promoter::GUS reporter construct used for this study. A $1.9-\mathrm{kb}$ promoter region of SAG13 was used to drive the expression of $\beta$-glucuronidase (GUS) in transgenic plants. B, Four-week-old leaves of transgenic SAG13 promoter::GUS plants were treated on one half only with Pseudomonas syringae pv. tomato DC3000 (avrRpm1), C, DC3000 (avrRpt2), and D, Botrytis cinerea, and tissue was harvested for staining at 12 and $24 \mathrm{~h}$ post-treatment (hpt) and 5 days post-treatment, respectively. E, Further stress treatments were done by wounding leaves on one half with toothed forceps or $\mathbf{F}$, treatment with paraquat (PQ) to cause reactive oxygen species induction, and samples were collected at $24 \mathrm{hpt}$ for both treatments. Tissues were also stained at various stages of development and in various organs: G, 5-day-old seedlings grown on plates, $\mathbf{H}$, rosette leaves at various stages of senescence, $\mathbf{I}, \mathbf{J}, \mathbf{K}$, and $\mathbf{L}$, floral buds at various stages of development, $\mathbf{M}$, senescing flower with protruding silique, $\mathbf{N}$, siliques at various stages of development, and $\mathbf{O}$, the abscission zone in a ripening silique. Except for the 5-day-old seedling shown in G, all the materials used for GUS analysis were from plants grown in soil in long-day conditions at room temperature under cool white light. 
Subsequently, SAG13 expression has been widely used as a marker for various processes associated with cell death induction during PCD, HR, and necrosis. This study demonstrated that $S A G 13$ is differentially regulated by multiple pathogens, and we provide evidence that this pathogen-induced expression is effector-triggered, as the induction is abolished in bacterial mutants having a dysfunctional T3SS. Our results show that $S A G 13$ is induced rapidly and strongly during HR cell death, while $S A G 13$ expression is strongly reduced in etrl (affecting ET signaling) and $n d r l$ mutants (which cannot induce the proper defense response and display an impaired HRmediated cell death during incompatible interactions). This result is not surprising, as NDRl and ETRl are required for ROS-dependent cell death during activation of HR against avirulent bacterial pathogens (Century et al. 1995, 1997; Devadas et al. 2002). Similarly, EIN2 and ETR1 have been shown to be required for HR activation (Bent et al. 1992). ET is a major factor not only in the induction of natural senescence but also in pathogen-induced cell death (Broekaert et al. 2006; Hensel et al. 1993). The etrl mutant shows delayed senescence (Hensel et al. 1993; Jing et al. 2005). A slight reduction in SAG13 induction in pad4 and coil mutants (Fig. 6B) suggests that these genes might partially contribute to $S A G 13$ induction in response to this avirulent pathogen. Further, in relation to both ET and SA, the reduction in pathogen-induced SAG13 levels in the SA and ET mutants in this study suggests that SAG13 functions downstream of the reception or production and amplification of the pathogen-triggered defense activation during compatible and incompatible interactions.

Cellular levels of ROS are higher during senescence, and higher levels of ROS have been shown to contribute to progression of senescence in both plants and animals (Jabs 1999). Senescence marker genes have been used extensively to monitor the progression of senescence and cell death in plants exposed to ROS (Brodersen et al. 2002; John et al. 2001; Miller et al. 1999). Among various markers of senescence, SAG13 was one of the few $S A G s$ that was visibly and strictly upregulated in the above studies. Various species of ROS play an important role during pathogenesis; our results indicate a stronger induction of $S A G 13$ by avirulent pathogens (that coincides with a rapid oxidative burst responsible for HR induced during such interactions), susceptibility to $B$. cinerea, and reduced accumulation of anthocyanin in sag 13 mutants, instigating us to investigate the role of ROS in SAG13 upregulation. It should be noted that ROS might be employed by the necrotrophic pathogen as a ploy to gain access to plants resources and can be a byproduct of the infection process (Glazebrook 2005; Torres 2010). Furthermore, ROS not only act as a defense mechanism to limit the spread of a pathogen at the site of infection but also as a secondary messenger in various signaling pathways during defense responses and in various developmental processes (Jabs 1999; Levine et al. 1994; Mittler 2017).

Furthermore, most of the LMM defense responses are constitutively activated along with elevated levels of ROS and result in increased cell death (Lorrain et al. 2003). In this context, SAG13 induction was the strongest in the lesion-positive leaves of the lsdl mutant, in which cell death from exposure to strong light has been shown to occur in a manner dependent on a superoxide radical (Dietrich et al. 1997; Jabs et al. 1996). Our results show that SAG13 shows enhanced resistance to the biotrophic pathogen P. syringae like many of the LMMs, including acd2, acd6, cpn1, hrll, lsdl, and cpr5 (Devadas et al. 2002; Dietrich et al. 1997; Greenberg and Ausubel 1993; Lorrain et al. 2003; Yao and Greenberg 2006). The upregulation of SAG13 in response to higher intrinsic levels of ROS through chemical treatments suggests a role of SAG13 in ROS-triggered induction of cell death in response to various pathogens and other stresses. The plant pigment anthocyanin has been known to act as a protectant against the deleterious effects of ROS in response to biotic and abiotic stresses and is a factor responsible for enhanced resistance against the necrotrophic pathogen $B$. cinerea ( $\mathrm{Lu}$ et al. 2017; Zhang et al. 2013). Combining the facts that $S A G 13$ is a positive regulator of senescence and that sag 13 mutants fail to accumulate anthocyanin under stress (high light and nutrient starvation) in comparison with the wild-type Col-0, a hypothesis for $S A G 13$ function can be proposed. It is possible that the stress-induced SAG13 helps to maintain cellular integrity, in the context of cell death processes, by regulating the redox state of the cell in a manner that may involve the production or accumulation of anthocyanins. Such an effect is dependent on light, as is supported from the following observations: i) SAG13 is induced in the lesion-positive leaves of the LMMs in which light has been shown to induce ROS and leads to cell death, ii) SAG13 is strongly induced by PQ and is required for seedling development in the presence of PQ, a chemical that is specifically associated with light-promoted superoxide production, leading to a cell death process visually similar to pathogen-induced HR, and iii) anthocyanin accumulation in the wild-type Col-0 detached leaf assays was induced more strongly with increased duration and strength of light exposure. This accumulation was drastically reduced in sag13 mutants.

Our results show that the presence or ectopic expression of SAG13 aids the plant in fighting necrotrophic fungal pathogens and is required for proper seed germination and plant survival under oxidative stress-inducing conditions. Our results showing diminished anthocyanin accumulation in sagl3 mutants under high-intensity light and nutrient-limiting conditions also hint at its role as a protectant under abiotic stresses in a manner that could involve the stress-induced protective function of anthocyanins. In contrast, the biotrophic bacteria Pseudomonas syringae benefits from the absence of $S A G 13$, indicating that pathogens with differing infection strategies have evolved to exploit plant growth and developmental, metabolic, and defense processes.

We hypothesize that since SAG13 is induced early during developmental senescence (in leaves, floral organs, and seeds) and seems to localize to the cell membrane (Supplementary Fig. S4), it is most likely involved in the metabolism of ROS by controlling transport of metabolites across the membrane. Such a scenario would help explain the contradicting phenotypes of sag $13 \mathrm{mu}-$ tants against the two different classes of pathogens. While its presence can be taken advantage of by the bacterial foliar biotroph that thrives on keeping the host alive while accessing its nutrients from the apoplast (hence, sag13 mutants are resistant to Pseudomonas spp.), the lifestyle of a fungal necrotroph is not adapted to such a situation in which $S A G 13$ may help reduce, slow down, or stop pathogen-induced ROS burst resulting in necrotic cell death and the subsequent nutrient loss from host cells (hence, sag13 mutants are susceptible to $B$. cinerea).

In summary, we have determined that $S A G 13$, a widely used marker of senescence in plants, is involved in regulating darkinduced leaf senescence and defense responses against multiple pathogens and in response to oxidative stress (Supplementary Fig. S5). A variety of stimuli induce $S A G 13$, most likely through the production of ROS. SAG13 is required for normal progression of dark-induced senescence and is expressed in senescing leaves, flowers, and fruits, and loss- or gain-of function of SAG13 has varying consequences during defense, depending on the pathogen lifestyle. SAG13 positively regulates resistance to Botrytis cinerea and negatively regulates resistance to Pseudomonas syringae. Furthermore, SAG13 promotes senescence, photoprotection, anthocyanin accumulation, and tolerance to oxidative stress. This knowledge can be utilized for genetic improvements and formulations of agricultural practice strategies for crops with prolonged storage shelf-life of leaves, 
flowers, and fruits under dark and low-light conditions as well as any accompanying opportunistic pathogen infection that could diminish their market value and result in economic losses. Since SAG13 is conserved in many plant species, including those of economic significance, the findings of this study would have direct practical implications for crop improvement.

\section{MATERIALS AND METHODS}

\section{Plant materials and growth conditions.}

All Arabidopsis thaliana plants used were of the Colombia (Col-0) ecotype that served as the wild type unless mentioned otherwise. Plants were grown in soil (Metro-Mix 360, Sun Gro Horticulture) or on plates containing one-half Murashige Skoog (1/2-MS) medium (pH 5.8, 0.8\% agar) supplemented with appropriate antibiotics for selection. Growth chambers were kept at 22 and $20^{\circ} \mathrm{C}$ (day and night, respectively), 60 to $70 \%$ relative humidity, and at a photosynthetic photon flux density of 75 to $100 \mu \mathrm{mol} \mathrm{m} \mathrm{m}^{-2} \mathrm{~s}^{-1}$ with a 10-h light and 14-h dark photoperiod for short day conditions, 12-h light and 12-h dark photoperiod for long day (LD) growth conditions. The 35S::OxSAG13 and PromSAG13::GUS constructs were used to transform the wildtype Col-0 plants via floral dip following the method of Clough and Bent (1998). $T_{1}$ generation transformants were selected on plates supplemented with $50 \mathrm{mg}$ of kanamycin per milliliter for $35 S:: O x S A G 13$ or $20 \mathrm{mg}$ of hygromycin per milliliter for PromSAG13::GUS constructs. Homozygous lines were selected in subsequent generations and were used for further study.

\section{Identification of sag13 T-DNA insertion mutants.}

T-DNA insertion lines sag13-1 (SALK_021619) and sag13-2 (SAIL_700_G12) were obtained from the Arabidopsis Biological Resource Center SALK T-DNA collection (Alonso et al. 2003) and the SAIL T-DNA collection (Sessions et al. 2002), respectively. Sequences flanking the T-DNA insertion sites were amplified using the $S A G 13$ gene-specific reverse primer (5'-ATGGCAAAGGAAGGGGGCTTG-3') and T-DNA left border primers $\left(5^{\prime}\right.$-TGGTTCACGTAGTGGGCCATCG$3^{\prime}$ ) for sag13-1, gene-specific primer (5'-TGGCATAGTCTTG AAGGAAAAACCGTTAAC-3') and (5'-TAGCATCTGAATTTC ATAACCAATCTCGATACAC-3') for sag 13-2, respectively. Amplified products were sequenced to determine the site of insertion of T-DNA in each line. Homozygous mutants were also confirmed for transcript levels by Northern blot analyses of RNA extracted from pathogen-treated mutant lines and hybridized with full-length $S A G 13$ probes.

\section{Construction of 35S::SAG13 overexpression and PromSAG13::GUS transgenic lines.}

To construct transgenic plants overexpressing SAG13, fulllength $S A G 13$ cDNA was amplified by reverse transcription PCR (RT-PCR). For cloning purposes, $A s c \mathrm{I}$ and $S w a \mathrm{I}$ restriction sites were introduced at the $5^{\prime}$ end of the forward primer and at the $3^{\prime}$ end of the reverse primer, respectively. The sequences of the forward and reverse primers were $5^{\prime}$-GGCGCGCCCAAGG AATGGCAAAGGAAGGGG-3' and 5' ATATGTGTTTTATGGCATAG-3', respectively (restriction sites are underlined). The PCR-amplified products were cloned into the pCR2.1-TOPO TA cloning vector (Invitrogen) to construct TOPO$S A G 13$. The sequence of the PCR amplified product was confirmed by DNA sequencing. The insert was isolated by restriction digestion, excision on an agarose gel, and cloned downstream of the CaMV $35 S$ promoter in AscI-SwaI-digested binary vector pSR3000 (derived from pCAMBIA 2300). Arabidopsis wild-type Col-0 plants were transformed by Agrobacterium (Clough and Bent 1998), and transgenic plants were selected on 1/2-MS medium ( $\mathrm{pH} 5.8,0.8 \%$ agar) containing $50 \mu \mathrm{g} / \mathrm{ml}$ kanamycin.
To prepare the construct for use in transgenic plants expressing PromSAG13::GUS, a 1.9-kb DNA sequence fragment upstream of the transcription start site was amplified from the wild-type Col-0 genomic DNA, using Platinum Taq High Fidelity DNA polymerase (Invitrogen), and was cloned into the pCR8/GW/TOPO vector (Invitrogen). Primers used for amplification were 5'-CCATTATGGATATTCTCCCAATCTATC-3' (forward) and 5'-GGAATTAGTGTTAAAGGATGGACCCT-3' (reverse). The insert was sequenced and was then recombined, using LR Clonase enzyme (Invitrogen), into the plant transformation vector pMDC163 (Curtis and Grossniklaus 2003). The construct was used to transform the wild-type Col-0 plants via an Agrobacterium floral dip method (Clough and Bent 1998). Transgenic plants were selected on 1/2-MS medium ( $\mathrm{pH} 5.8$, $0.8 \%$ agar) supplemented with $20 \mu \mathrm{g}$ of hygromycin per milliliter.

\section{Plant inoculation and measurement of in-planta bacterial growth.}

Pseudomonas syringae for plant inoculation were provided by B. Kunkel (Washington University). Infiltration of plants and pathogen growth assays using different Pseudomonas strains were performed as described by Tornero and Dangl (2002). Briefly, for agroinfiltration, plants were pressureinfiltrated with a needleless syringe, and the trays were kept covered with humidity domes for 3 to $6 \mathrm{~h}$ under light. Under LD conditions, leaf yellowing and water-soaked lesion symptoms were monitored from 3 to 5 days for the appearance of disease symptoms. At least eight plants per genotype per replicate were collected randomly for pathogen growth assays. Three leaf punches per plant were taken, using a standard (6-mmdiameter) paper hole puncher, and bacteria were quantified as described by Tornero and Dangl (2002). Serial dilutions were plated on Luria Bertani media supplemented with $50 \mu \mathrm{g}$ of rifampicin per milliliter and $50 \mu \mathrm{g}$ of kanamycin per milliliter and were incubated at $28^{\circ} \mathrm{C}$ for 36 to $48 \mathrm{~h}$. Bacterial colonyforming units (CFU) per leaf disc per genotype were counted and graphed. Statistical analyses were performed using analysis of variance (ANOVA) followed by posthoc pairwise comparisons using Tukey's honestly significant difference (HSD). Each experiment was performed at least three times with similar results.

For the fungal growth assays, Botrytis cinerea (B05.10 strain) was obtained from H. Lu (University of Maryland, Baltimore, MD, U.S.A.). Pathogen inoculation was done as described by Ferrari et al. (2003). Briefly, the pathogen was grown on potato dextrose agar medium. The spores were harvested and were suspended in potato dextrose broth, and the detached leaves were placed on 1/2-MS medium ( $\mathrm{pH} 5.8,0.8 \%$ agar) and inoculated with a single 10- $\mu 1$ drop of spore suspension $\left(2.5 \times 10^{5}\right.$ spores $\left./ \mathrm{ml}\right)$. The Petri plates were tightly sealed with parafilm to maintain humidity and were kept at room temperature under LD conditions until the appearance of yellow necrotic lesions. Typically such necrotic lesions appeared visibly earlier for sag13 mutants in comparison with the wildtype Col-0 (3 to 5 days post-treatment [dpt]), while the lesion development was delayed for $35 S:: S A G 13$ plants in comparison with the respective wild-type Col-0 control (5 to $7 \mathrm{dpt}$ ). The lesion diameter was measured for at least eight leaves per genotype per replicate and the average lesion area was plotted. Statistical testing was carried out using ANOVA followed by posthoc pairwise comparisons using Tukey's HSD. Each experiment was performed at least three times with similar results.

\section{Northern blot analysis and RT-PCR.}

Tissue samples from inoculated and uninoculated plants were flash-frozen in liquid nitrogen upon collection at different intervals postinoculation. Total RNA was isolated using Trizol reagent (Invitrogen) according to the manufacturer's protocol. 
RNA gel blot analysis was performed following the procedure of Devadas et al. (2002). Probes for hybridizing were PCRamplified from cDNA, using gene-specific primers 5'-ATGGCA

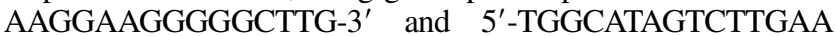
GGAAAAACCGTTAAC-3' for $S A G 13$, and 5'-CCACAAGAT TATCTAAGGGTTC-3' and 5'-GGCTTCTCGTTCACATAAT TCC-3' for PR1. Probes used for Northern blot were the purified PCR products. PCR probes were radiolabeled as previously described by Pilloff et al. (2002). For semiquantitative RT-PCR, $2 \mu \mathrm{g}$ of total RNA for each sample was reverse transcribed with Superscript III reverse transcription (Invitrogen) according to the manufacturer's protocol. The cDNA was diluted 1:2 with doubledistilled $\mathrm{H}_{2} \mathrm{O}\left(\mathrm{ddH}_{2} \mathrm{O}\right)$ and $1 \mu \mathrm{l}$ of cDNA was used as a template in RT-PCR reactions.

\section{Histochemical assay for GUS activity.}

Transgenic plants for pathogen treatment were selected on 1/2-MS medium (pH 5.8, $0.8 \%$ agar) supplemented with $20 \mu \mathrm{g}$ of hygromycin per milliliter. Histochemical analyses for GUS activity were carried out in three or four independent transgenic lines for each tissue, as described by Jagadeeswaran et al. (2007). Briefly, tissue samples were incubated overnight at $37^{\circ} \mathrm{C}$ in GUS assay buffer $\left(50 \mathrm{mM}\right.$ phosphate buffer $\left[\mathrm{Na}_{3} \mathrm{PO}_{4}\right]$ at $\mathrm{pH} 7.2,0.5 \mathrm{mM} \mathrm{K}_{3}\left[\mathrm{Fe}(\mathrm{CN})_{6}\right], 0.5 \mathrm{mM} \mathrm{K}_{4}\left[\mathrm{Fe}(\mathrm{CN})_{6}\right], 2 \mathrm{mM}$ 5-bromo-4-chloro-3-indoyl- $\beta$-D-glucoronic acid. After staining, samples were cleared of chlorophyll in $70 \%$ ethanol multiple times for 2 to 3 days at room temperature.

For bacterial treatments, the right half of the abaxial side of undetached leaves were pressure-infiltrated with a needleless syringe with the respective bacterial suspension in $10 \mathrm{mM} \mathrm{MgCl}_{2}$ at a titer of $5 \times 10^{7} \mathrm{CFU} / \mathrm{ml}$, and the samples were collected at 24 hpt for GUS analysis. For the PQ and wounding treatment samples, detached leaves were placed on 1/2-MS medium $(\mathrm{pH}$ $5.8,0.8 \%$ agar) after pressure-infiltrating the leaves on the adaxial side with $50 \mu \mathrm{M}$ of PQ in water. For wounding treatment, the leaves were wounded with toothed forceps on one side of the leaf. Samples were collected at $24 \mathrm{hpt}$.

For fungal treatments analyzed by GUS assays, detached leaves were placed on plain 1/2-MS medium $(\mathrm{pH} 5.8,0.8 \%$ agar). A $10 \mu \mathrm{l}$ drop of $B$. cinerea spores at a density of $5 \times 10^{5}$ spores $/ \mathrm{ml}$ was drop inoculated at the center of leaf. The leaves were taken at different days after treatment for GUS assays.

\section{Construction of SAG13-GFP (green fluorescent protein) plasmid and transient expression assay.}

LR Clonase enzyme (Invitrogen) was used to recombine a fulllength $S A G 13$ insert from the $\mathrm{pCR} 8 / \mathrm{GW} / \mathrm{TOPO}$ plasmid described above into the $p M D C 83$ plasmid (Curtis and Grossniklaus 2003) to produce the $35 S:: S A G 13-G F P$ fusion construct. The sequence of the amplified product was compared with the messenger RNA (mRNA) sequences available on the TAIR database to confirm that the correct full-length cDNA was amplified. Transient expression assays in onion epidermal peels were carried out following the procedure described by Dutta et al. (2017). In brief, the fusion plasmid (35S::SAG13-GFP) was coated onto gold particles, and transient expression assays in onion epidermal peels were performed, using $1-\mu \mathrm{m}$ gold microcarriers with a Biolistic PDS-1000/He DNA delivery system (Bio-Rad) at 900 pounds per square inch, following manufacturer instructions. The transformed cells were incubated overnight in the dark at room temperature, and the expression of the SAG13 fusion protein was observed using an Olympus BX60 microscope under GFP filters.

\section{Chemical treatments.}

For oxidative stress treatments, leaves were infiltrated with a needleless syringe, on the abaxial side, with aqueous solutions of $50 \mu \mathrm{M}$ PQ (methyl viologen, N, N'-dimethyl-4,4'-bipyridinium dichloride), $10 \mathrm{mM} \mathrm{H}_{2} \mathrm{O}_{2}, 10 \mathrm{mM}$ 3-AT, or $\mathrm{ddH}_{2} \mathrm{O}$ as control. One-microliter of flg22 peptide in $\mathrm{MgCl}_{2}$ buffer was pressureinfiltrated with a needleless syringe and at different hours after treatment, and collected samples were flash frozen in liquid nitrogen and were stored at $-80^{\circ} \mathrm{C}$ until further use. All chemicals were purchased from Sigma Chemical Co. unless noted otherwise.

\section{Detached leaf dark-induced senescence assay and pigment estimation.}

The detached-leaf senescence assay was performed with modification from the procedure described by Fan et al. (1997). Essentially, fully expanded rosette leaves from 5- to 6-week-old soil-grown plants were taken in duplicates, on square Petri plates, on a moist Whatman no. 3 paper to maintain internal humidity. The plates were kept under light at room temperature under similar conditions used for controlled plant-growth chambers or were wrapped in double layer of aluminum foil and were kept as described above for dark treatment. Typically, the symptoms appeared 3 to $7 \mathrm{dpt}$. In various biological replicates, visible senescence always appeared 2 to 3 days early for $35 S:: S A G 13$ plants in comparison with the wild-type Col-0 control (thus, the experiment was terminated at 3 to $4 \mathrm{dpt}$ ), while the appearance of this phenotype was delayed by 1 to 2 days in sag 13 mutants in comparison with the respective the wild-type Col-0 control (hence, the experiment was terminated at 5 to $7 \mathrm{dpt}$ ). Pictures of the senescing leaves were taken when the senescence phenotype was apparent and chlorophyll was isolated from light- and darktreated leaves as described by McCabe et al. (2001). Briefly, chlorophyll was extracted from homogenized $1-\mathrm{cm}^{2}$ circular leaf discs with or without dark treatment in $80 \%$ acetone in water overnight, in dark, at $4^{\circ} \mathrm{C}$. After a brief centrifugation, the supernatant was extracted, and chlorophyll $\mathrm{a}$ and $\mathrm{b}$ contents were determined spectrophotometrically, by measuring absorbance at 645 and $657 \mathrm{~nm}$. Chlorophyll content was calculated using the equation: $\left(20.2 \times \mathrm{A}_{645}\right)+\left(8.02 \times \mathrm{A}_{657}\right)$ (Arnon 1949). At least eight to ten independent leaf samples per genotype per treatment were used. Statistical testing was carried out using ANOVA followed by posthoc pairwise comparisons using Tukey's HSD. The experiment was repeated at least three times with similar results. Anthocyanin was isolated from each leaf sample and was calculated as total anthocyanin content at $\mathrm{A}_{530}$ per gram of fresh weight (Nakata et al. 2013).

\section{ACKNOWLEDGMENTS}

The authors acknowledge assistance from T. Fokken, A. Lau, and other members of the Raina Lab for their help with maintenance of plants, pathogens used, and some plant data collection. Bacterial pathogens Pseudomonas syringae pv. tomato DC3000 and P. syringae pv. maculicola ES4326 were obtained from B. Kunkel. We thank A. Collmer for DC3000 $(h r c C)$ and DC3000 ( $h r c U)$ T3SS mutants, and G. Martin for Pseudomonas syringae pv. tabaci. We also thank J. Dangl, J. Greenberg, X. Dong, and M. Wildermuth for supplying seeds of $l s d 1$, acd2, nprl-1, and eds1-16, respectively.

\section{AUTHOR-RECOMMENDED INTERNET RESOURCE}

The Arabidopsis Information Resource (TAIR) AT2G29350 page: https://www.arabidopsis.org/servlets/TairObject?id=32025\&type=locus

\section{LITERATURE CITED}

A.-H.-Mackerness, S., John, C. F., Jordan, B., and Thomas, B. 2001. Early signaling components in ultraviolet-B responses: Distinct roles for different reactive oxygen species and nitric oxide. FEBS Lett. 489:237-242.

A.-H.-Mackerness, S., Surplus, S. L., Blake, P., John, C. F., BuchananWollaston, V., Jordan, B. R., and Thomas, B. 1999. Ultraviolet-Binduced stress and changes in gene expression in Arabidopsis thaliana: Role of signalling pathways controlled by jasmonic acid, ethylene and reactive oxygen species. Plant Cell Environ. 22:1413-1423. 
Alfano, J. R., and Collmer, A. 1997. The type III (Hrp) secretion pathway of plant pathogenic bacteria: Trafficking harpins, Avr proteins, and death. J. Bacteriol. 179:5655-5662.

Alonso, J. M., Stepanova, A. N., Leisse, T. J., Kim, C. J., Chen, H., Shinn, P., Stevenson, D. K., Zimmerman, J., Barajas, P., Cheuk, R., Gadrinab, C., Heller, C., Jeske, A., Koesema, E., Meyers, C. C., Parker, H., Prednis, L., Ansari, Y., Choy, N., Deen, H., Geralt, M., Hazari, N., Hom, E., Karnes, M., Mulholland, C., Ndubaku, R., Schmidt, I., Guzman, P., Aguilar-Henonin, L., Schmid, M., Weigel, D., Carter, D. E., Marchand, T., Risseeuw, E., Brogden, D., Zeko, A., Crosby, W. L., Berry, C. C., and Ecker, J. R. 2003. Genomewide insertional mutagenesis of Arabidopsis thaliana. Science 301:653-657.

Arnon, D. I. 1949. Copper enzymes in isolated chloroplasts. Polyphenoloxidase in Beta vulgaris. Plant Physiol. 24:1-15.

Bent, A. F., Innes, R. W., Ecker, J. R., and Staskawicz, B. J. 1992. Disease development in ethylene-insensitive Arabidopsis thaliana infected with virulent and avirulent Pseudomonas and Xanthomonas pathogens. Mol. Plant-Microbe Interact 5:372-378.

Breeze, E., Harrison, E., McHattie, S., Hughes, L., Hickman, R., Hill, C., Kiddle, S., Kim, Y. S., Penfold, C. A., Jenkins, D., Zhang, C., Morris, K., Jenner, C., Jackson, S., Thomas, B., Tabrett, A., Legaie, R., Moore, J. D., Wild, D. L., Ott, S., Rand, D., Beynon, J., Denby, K., Mead, A., and Buchanan-Wollaston, V. 2011. High-resolution temporal profiling of transcripts during Arabidopsis leaf senescence reveals a distinct chronology of processes and regulation. Plant Cell 23:873-894.

Breeze, E., Harrison, E., Page, T., Warner, N., Shen, C., Zhang, C., and Buchanan-Wollaston, V. 2008. Transcriptional regulation of plant senescence: From functional genomics to systems biology. Plant Biol Stuttg 10 (Suppl 1):99-109.

Brock, A., Brandt, W., and Dräger, B. 2008. The functional divergence of shortchain dehydrogenases involved in tropinone reduction. Plant J. 54:388-401.

Brodersen, P., Petersen, M., Pike, H. M., Olszak, B., Skov, S., Odum, N., Jørgensen, L. B., Brown, R. E., and Mundy, J. 2002. Knockout of Arabidopsis accelerated-cell-death11 encoding a sphingosine transfer protein causes activation of programmed cell death and defense. Genes Dev. 16:490-502.

Broekaert, W. F., Delauré, S. L., De Bolle, M. F. C., and Cammue, B. P. A. 2006. The role of ethylene in host-pathogen interactions. Annu. Rev. Phytopathol. 44:393-416.

Cancel, J. D., and Larsen, P. B. 2002. Loss-of-function mutations in the ethylene receptor ETR1 cause enhanced sensitivity and exaggerated response to ethylene in Arabidopsis. Plant Physiol. 129:1557-1567.

Cao, H., Bowling, S. A., Gordon, A. S., and Dong, X. 1994. Characterization of an Arabidopsis mutant that is nonresponsive to inducers of systemic acquired resistance. Plant Cell 6:1583-1592.

Cao, H., Glazebrook, J., Clarke, J. D., Volko, S., and Dong, X. 1997. The Arabidopsis NPR1 gene that controls systemic acquired resistance encodes a novel protein containing ankyrin repeats. Cell 88:57-63.

Century, K. S., Holub, E. B., and Staskawicz, B. J. 1995. NDR1, a locus of Arabidopsis thaliana that is required for disease resistance to both a bacterial and a fungal pathogen. Proc. Natl. Acad. Sci. U.S.A. 92:6597-6601.

Century, K. S., Shapiro, A. D., Repetti, P. P., Dahlbeck, D., Holub, E. B., and Staskawicz, B. J. 1997. NDR1, a pathogen-induced component required for Arabidopsis disease resistance. Science 278:1963-1965.

Chen, Q. F., Xu, L., Tan, W. J., Chen, L., Qi, H., Xie, L. J., Chen, M. X., Liu, B. Y., Yu, L. J., Yao, N., Zhang, J. H., Shu, W., and Xiao, S. 2015. Disruption of the Arabidopsis defense regulator genes SAG101, EDS1, and PAD4 confers enhanced freezing tolerance. Mol. Plant 8:1536-1549.

Chen, Y., Wang, Y., Huang, J., Zheng, C., Cai, C., Wang, Q., and Wu, C. A. 2017. Salt and methyl jasmonate aggravate growth inhibition and senescence in Arabidopsis seedlings via the JA signaling pathway. Plant Sci. 261:1-9.

Clough, S. J., and Bent, A. F. 1998. Floral dip: A simplified method for Agrobacterium-mediated transformation of Arabidopsis thaliana. Plant J. 16:735-743.

Coll, N. S., Epple, P., and Dangl, J. L. 2011. Programmed cell death in the plant immune system. Cell Death Differ. 18:1247-1256.

Curtis, M. D., and Grossniklaus, U. 2003. A Gateway cloning vector set for high-throughput functional analysis of genes in planta. Plant Physiol. 133:462-469.

Davies, P. J., and Gan, S. 2012. Towards an integrated view of monocarpic plant senescence. Russ. J. Plant Physiol. 59:467-478.

Delaney, T. P., Uknes, S., Vernooij, B., Friedrich, L., Weymann, K., Negrotto, D., Gaffney, T., Gut-Rella, M., Kessmann, H., Ward, E., and Ryals, J. 1994. A central role of salicylic acid in plant disease resistance. Science 266:1247-1250.

Devadas, S. K., Enyedi, A., and Raina, R. 2002. The Arabidopsis hrll mutation reveals novel overlapping roles for salicylic acid, jasmonic acid and ethylene signalling in cell death and defence against pathogens. Plant J. 30:467-480.
Dewdney, J., Reuber, T. L., Wildermuth, M. C., Devoto, A., Cui, J., Stutius, L. M., Drummond, E. P., and Ausubel, F. M. 2000. Three unique mutants of Arabidopsis identify eds loci required for limiting growth of a biotrophic fungal pathogen. Plant J. 24:205-218.

Dickman, M. B., and Fluhr, R. 2013. Centrality of host cell death in plantmicrobe interactions. Annu. Rev. Phytopathol. 51:543-570.

Dietrich, R. A., Richberg, M. H., Schmidt, R., Dean, C., and Dangl, J. L. 1997. A novel zinc finger protein is encoded by the Arabidopsis LSD1 gene and functions as a negative regulator of plant cell death. Cell 88: 685-694.

Durrant, W. E., and Dong, X. 2004. Systemic acquired resistance. Annu. Rev. Phytopathol. 42:185-209.

Dutta, A., Choudhary, P., Caruana, J., and Raina, R. 2017. JMJ27, an Arabidopsis H3K9 histone demethylase, modulates defense against Pseudomonas syringae and flowering time. Plant J. 91:1015-1028.

Espinoza, C., Medina, C., Somerville, S., and Arce-Johnson, P. 2007. Senescence-associated genes induced during compatible viral interactions with grapevine and Arabidopsis. J. Exp. Bot. 58:3197-3212.

Fan, L., Zheng, S., and Wang, X. 1997. Antisense suppression of phospholipase D $\alpha$ retards abscisic acid- and ethylene-promoted senescence of postharvest Arabidopsis leaves. Plant Cell 9:2183-2196.

Ferrari, S., Plotnikova, J. M., De Lorenzo, G., and Ausubel, F. M. 2003. Arabidopsis local resistance to Botrytis cinerea involves salicylic acid and camalexin and requires EDS4 and PAD2, but not SID2, EDS5 or PAD4. Plant J. 35:193-205.

Feys, B. J., Moisan, L. J., Newman, M. A., and Parker, J. E. 2001. Direct interaction between the Arabidopsis disease resistance signaling proteins, EDS1 and PAD4. EMBO J. 20:5400-5411.

Gaffney, T., Friedrich, L., Vernooij, B., Negrotto, D., Nye, G., Uknes, S., Ward, E., Kessmann, H., and Ryals, J. 1993. Requirement of salicylic Acid for the induction of systemic acquired resistance. Science 261:754-756.

Gan, S., and Amasino, R. M. 1995. Inhibition of leaf senescence by autoregulated production of cytokinin. Science 270:1986-1988.

Glässgen, W. E., Rose, A., Madlung, J., Koch, W., Gleitz, J., and Seitz, H. U. 1998. Regulation of enzymes involved in anthocyanin biosynthesis in carrot cell cultures in response to treatment with ultraviolet light and fungal elicitors. Planta 204:490-498.

Glazebrook, J. 2005. Contrasting mechanisms of defense against biotrophic and necrotrophic pathogens. Annu. Rev. Phytopathol. 43:205-227.

Greenberg, J. T., and Ausubel, F. M. 1993. Arabidopsis mutants compromised for the control of cellular damage during pathogenesis and aging. Plant J. 4:327-341.

Greenberg, J. T., Guo, A., Klessig, D. F., and Ausubel, F. M. 1994 Programmed cell death in plants: A pathogen-triggered response activated coordinately with multiple defense functions. Cell 77:551-563.

Hensel, L. L., Grbić, V., Baumgarten, D. A., and Bleecker, A. B. 1993. Developmental and age-related processes that influence the longevity and senescence of photosynthetic tissues in Arabidopsis. Plant Cell 5: 553-564.

Himelblau, E., and Amasino, R. M. 2001. Nutrients mobilized from leaves of Arabidopsis thaliana during leaf senescence. J. Plant Physiol. 158: 1317-1323.

Hofius, D., Tsitsigiannis, D. I., Jones, J. D., and Mundy, J. 2007. Inducible cell death in plant immunity. Semin. Cancer Biol. 17:166-187.

Jabs, T. 1999. Reactive oxygen intermediates as mediators of programmed cell death in plants and animals. Biochem. Pharmacol. 57:231-245.

Jabs, T., Dietrich, R. A., and Dangl, J. L. 1996. Initiation of runaway cell death in an Arabidopsis mutant by extracellular superoxide. Science 273: 1853-1856.

Jagadeeswaran, G., Raina, S., Acharya, B. R., Maqbool, S. B., Mosher, S. L., Appel, H. M., Schultz, J. C., Klessig, D. F., and Raina, R. 2007. Arabidopsis GH3-LIKE DEFENSE GENE 1 is required for accumulation of salicylic acid, activation of defense responses and resistance to Pseudomonas syringae. Plant J. 51:234-246.

Jing, H. C., Hebeler, R., Oeljeklaus, S., Sitek, B., Stühler, K., Meyer, H. E., Sturre, M. J. G., Hille, J., Warscheid, B., and Dijkwel, P. P. 2008. Early leaf senescence is associated with an altered cellular redox balance in Arabidopsis cpr5/old1 mutants. Plant Biol Stuttg 10 (Suppl 1):85-98.

Jing, H. C., Schippers, J. H. M., Hille, J., and Dijkwel, P. P. 2005. Ethyleneinduced leaf senescence depends on age-related changes and $O L D$ genes in Arabidopsis. J. Exp. Bot. 56:2915-2923.

Jirage, D., Tootle, T. L., Reuber, T. L., Frost, L. N., Feys, B. J., Parker, J. E., Ausubel, F. M., and Glazebrook, J. 1999. Arabidopsis thaliana PAD4 encodes a lipase-like gene that is important for salicylic acid signaling. Proc. Natl. Acad. Sci. U.S.A. 96:13583-13588.

John, C. F., Morris, K., Jordan, B. R., Thomas, B., and A-H-Mackerness, S. 2001. Ultraviolet-B exposure leads to up-regulation of senescenceassociated genes in Arabidopsis thaliana. J. Exp. Bot. 52:1367-1373. 
Kabbage, M., Kessens, R., Bartholomay, L. C., and Williams, B. 2017. The life and death of a plant cell. Annu. Rev. Plant Biol. 68:375-404.

Katsir, L., Schilmiller, A. L., Staswick, P. E., He, S. Y., and Howe, G. A. 2008. COI1 is a critical component of a receptor for jasmonate and the bacterial virulence factor coronatine. Proc. Natl. Acad. Sci. U.S.A. 105: 7100-7105.

Landi, M., Tattini, M., and Gould, K. S. 2015. Multiple functional roles of anthocyanins in plant-environment interactions. Environ. Exp. Bot. 119:4-17.

Levine, A., Tenhaken, R., Dixon, R., and Lamb, C. 1994. $\mathrm{H}_{2} \mathrm{O}_{2}$ from the oxidative burst orchestrates the plant hypersensitive disease resistance response. Cell 79:583-593.

Li, Z., Peng, J., Wen, X., and Guo, H. 2012. Gene network analysis and functional studies of senescence-associated genes reveal novel regulators of Arabidopsis leaf senescence. J. Integr. Plant Biol. 54:526-539.

Lohman, K. N., Gan, S., John, M. C., and Amasino, R. M. 1994. Molecular analysis of natural leaf senescence in Arabidopsis thaliana. Physiol. Plant. 92:322-328.

Lorrain, S., Vailleau, F., Balagué, C., and Roby, D. 2003. Lesion mimic mutants: Keys for deciphering cell death and defense pathways in plants? Trends Plant Sci. 8:263-271.

Love, A. J., Milner, J. J., and Sadanandom, A. 2008. Timing is everything: Regulatory overlap in plant cell death. Trends Plant Sci. 13:589-595.

Lu, Y., Chen, Q., Bu, Y., Luo, R., Hao, S., Zhang, J., Tian, J., and Yao, Y. 2017. Flavonoid accumulation plays an important role in the rust resistance of malus plant leaves. Front. Plant Sci. 8:1286.

Maillard, A., Diquélou, S., Billard, V., Laîné, P., Garnica, M., Prudent, M. Garcia-Mina, J.-M., Yvin, J.-C., and Ourry, A. 2015. Leaf mineral nutrient remobilization during leaf senescence and modulation by nutrient deficiency. Front. Plant Sci. 6:317.

Mattila, H., Valev, D., Havurinne, V., Khorobrykh, S., Virtanen, O., Antinluoma, M., Mishra, K. B., and Tyystjärvi, E. 2018. Degradation of chlorophyll and synthesis of flavonols during autumn senescence-the story told by individual leaves. AoB Plants 10:ply028.

McCabe, M. S., Garratt, L. C., Schepers, F., Jordi, W. J. R. M., Stoopen, G. M., Davelaar, E., van Rhijn, J. H. A., Power, J. B., and Davey, M. R. 2001. Effects of $P(S A G 12)-I P T$ gene expression on development and senescence in transgenic lettuce. Plant Physiol. 127:505-516.

Miller, J. D., Arteca, R. N., and Pell, E. J. 1999. Senescence-associated gene expression during ozone-induced leaf senescence in Arabidopsis. Plant Physiol. 120:1015-1024.

Mittler, R. 2017. ROS are good. Trends Plant Sci. 22:11-19.

Nakata, M., Mitsuda, N., Herde, M., Koo, A. J. K., Moreno, J. E., Suzuki, K., Howe, G. A., and Ohme-Takagi, M. 2013. A bHLH-type transcription factor ABA-INDUCIBLE BHLH-TYPE TRANSCRIPTION FACTOR/ JA-ASSOCIATED MYC2-LIKE1, acts as a repressor to negatively regulate jasmonate signaling in Arabidopsis. Plant Cell 25:1641-1656.

Noctor, G., Mhamdi, A., and Foyer, C. H. 2016. Oxidative stress and antioxidative systems: Recipes for successful data collection and interpretation. Plant Cell Environ. 39:1140-1160.

Oh, S. A., Lee, S. Y., Chung, I. K., Lee, C.-H., and Nam, H. G. 1996. A senescence-associated gene of Arabidopsis thaliana is distinctively regulated during natural and artificially induced leaf senescence. Plant Mol. Biol. 30:739-754

Oh, S. A., Park, J.-H. H., Lee, G. I., Paek, K. H., Park, S. K., and Nam, H. G. 1997. Identification of three genetic loci controlling leaf senescence in Arabidopsis thaliana. Plant J. 12:527-535.

Park, J. H., Oh, S. A., Kim, Y. H., Woo, H. R., and Nam, H. G. 1998. Differential expression of senescence-associated mRNAs during leaf senescence induced by different senescence-inducing factors in Arabidopsis. Plant Mol. Biol. 37:445-454.

Pennell, R. I., and Lamb, C. 1997. Programmed cell death in plants. Plant Cell 9:1157-1168.

Pilloff, R. K., Devadas, S. K., Enyedi, A., and Raina, R. 2002. The Arabidopsis gain-of-function mutant dll1 spontaneously develops lesions mimicking cell death associated with disease. Plant J. 30:61-70.

Pré, M., Atallah, M., Champion, A., De Vos, M., Pieterse, C. M. J., and Memelink, J. 2008. The AP2/ERF domain transcription factor ORA59 integrates jasmonic acid and ethylene signals in plant defense. Plant Physiol. 147:1347-1357.

Quirino, B. F., Normanly, J., and Amasino, R. M. 1999. Diverse range of gene activity during Arabidopsis thaliana leaf senescence includes pathogen-independent induction of defense-related genes. Plant Mol Biol. 40:267-278.

Robatzek, S., Chinchilla, D., and Boller, T. 2006. Ligand-induced endocytosis of the pattern recognition receptor FLS2 in Arabidopsis. Genes Dev. 20:537-542.

Rogers, H. J. 2005. Cell death and organ development in plants. Curr. Top. Dev. Biol. 71:225-261.

Rubinstein, B. 2000. Regulation of cell death in flower petals. Plant Mol Biol. 44:303-318.

Salleh, F. M., Evans, K., Goodall, B., Machin, H., Mowla, S. B., Mur L. A. J., Runions, J., Theodoulou, F. L., Foyer, C. H., and Rogers, H. J. 2012. A novel function for a redox-related LEA protein (SAG21/AtLEA5) in root development and biotic stress responses. Plant Cell Environ. 35:418-429.

Senthil-Kumar, M., and Mysore, K. S. 2013. Nonhost resistance against bacterial pathogens: Retrospectives and prospects. Annu. Rev. Phytopathol. 51:407-427

Seo, P. J., Park, J. M., Kang, S. K., Kim, S. G., and Park, C. M. 2011. An Arabidopsis senescence-associated protein SAG29 regulates cell viability under high salinity. Planta 233:189-200.

Sessions, A., Burke, E., Presting, G., Aux, G., McElver, J., Patton, D., Dietrich, B., Ho, P., Bacwaden, J., Ko, C., Clarke, J. D., Cotton, D., Bullis, D., Snell, J., Miguel, T., Hutchison, D., Kimmerly, B., Mitzel, T., Katagiri, F., Glazebrook, J., Law, M., and Goff, S. A. 2002. A highthroughput Arabidopsis reverse genetics system. Plant Cell 14: 2985-2994

Thomas, H. 2013. Senescence, ageing and death of the whole plant. New Phytol. 197:696-711

Tornero, P., and Dangl, J. L. 2002. A high-throughput method for quantifying growth of phytopathogenic bacteria in Arabidopsis thaliana. Plant J. 28:475-481.

Torres, M. A. 2010. ROS in biotic interactions. Physiol. Plant. 138:414-429.

Van Durme, M., and Nowack, M. K. 2016. Mechanisms of developmentally controlled cell death in plants. Curr. Opin. Plant Biol. 29:29-37.

Wang, H. L., Guo, H., and Li, Z. 2019. Gene network analysis of senescence-associated genes in annual plants and comparative assessment of aging in perennials and animals. Transl. Med. Aging 3:6-13.

Weaver, L. M., and Amasino, R. M. 2001. Senescence is induced in individually darkened Arabidopsis leaves, but inhibited in whole darkened plants. Plant Physiol. 127:876-886.

Weaver, L. M., Gan, S., Quirino, B., and Amasino, R. M. 1998. A comparison of the expression patterns of several senescence-associated genes in response to stress and hormone treatment. Plant Mol. Biol. 37: 455-469.

Williams, B., and Dickman, M. 2008. Plant programmed cell death: Can't live with it; can't live without it. Mol. Plant Pathol. 9:531-544.

Wojciechowska, N., Sobieszczuk-Nowicka, E., and Bagniewska-Zadworna, A. 2018. Plant organ senescence - regulation by manifold pathways. Plant Biol Stuttg 20:167-181.

Wu, X. Y., Kuai, B. K., Jia, J. Z., and Jing, H. C. 2012. Regulation of leaf senescence and crop genetic improvement. J. Integr. Plant Biol. 54: 936-952.

Yao, N., and Greenberg, J. T. 2006. Arabidopsis ACCELERATED CELL DEATH2 modulates programmed cell death. Plant Cell 18:397-411.

Zhang, Y., Butelli, E., De Stefano, R., Schoonbeek, H. J., Magusin, A., Pagliarani, C., Wellner, N., Hill, L., Orzaez, D., Granell, A., Jones, J. D. and Martin, C. 2013. Anthocyanins double the shelf life of tomatoes by delaying overripening and reducing susceptibility to gray mold. Curr. Biol. 23:1094-1100.

Zheng, X. Y., Spivey, N. W., Zeng, W., Liu, P. P., Fu, Z. Q., Klessig, D. F., He, S. Y., and Dong, X. 2012. Coronatine promotes Pseudomonas syringae virulence in plants by activating a signaling cascade that inhibits salicylic acid accumulation. Cell Host Microbe 11:587-596. 